\title{
أدب الطقل الإفريقي .. الوجه الأبيض للقارة السمراء المفهوم- المحتوى- أهم الإشكاليات وسبل حلها تهات (أدب الطقل المغربي نموذجًا)
}

أ. دـ حمدي إبراهيم حافظ

أستاذ أصول التربية_ جامعة الأزهر

$$
\text { تقديم الدراسة: }
$$

أـ الإمكانيات والموارد الطبيعية:

إفريقيا كما تكتب نهايتها بالألف (إفريقيا)، أو بالتاء المربوطة (إفريقية)، هي ثاني أكبر قار ات العالم من حيث المساحة و السكان بعد قارة آسيا، حيث تبلغ مساحتها ـ مليون كيلو متر مربع، كما يبلغ عدد سكانها سر ا مليار نسمة طبقًا لإحصائيات 9 1 ـ با، وهي تضم

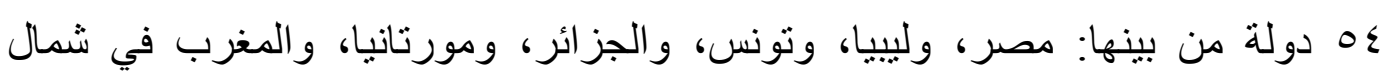

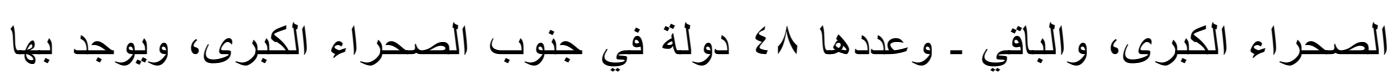
أطول أنهار العالم وهو نهر النيل، بالإضافة لأكبر صحر اء العالم وهي الصحر اء الكبرى، ويحدّها من الثمال والثرق كل من البحر المتوسط والبحر الأحمر، ومن الجنوب والغرب كل من المحيط الهندي والمحيط الأطلنطي، وبها أكبرممر مائي يخدم التجارة الدولية، وهو

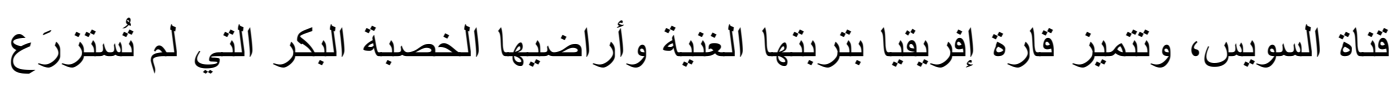
بعد، ومياهها المتجددة وأمطار ها الغزيرة طوال العام، وتركييتها الاجتماعية الطيبة غير المُعقّدة حيث لم تتجذر فيها بعد الرأسمالية المتوحشة المستغلة، مما يمكنها أن تقدم الحل المثالي لأزمة الغذاء في العالم التي بدأت تلوح معالمها في الأفق لتنذر بجوعٍ يهدد مئات الملايين من البشر في مختلف قار ات العالم حتى المتقدمة منها.

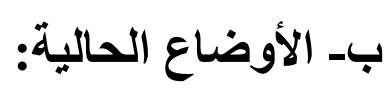

على الرغم من كل ماسبق ذكره من إمكانيات وموارد طبيعية، فإن إفريقيا كانت وماز الت هي القارة الأكثر فقرًا وتخلفًا من بين قار ات العالم، كما أن نسبة كبيرة من سكانها ما زالوا يعانون من الفقر والجهل والمرض، فمتوسط دخل المواطن الإفريقي اليومي في بعض الدول لا يتعدى (rر l) من الدولار، ويصل إلى (0لر) من الدولار في بعض 


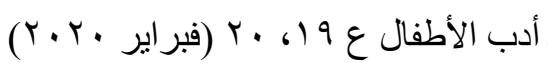

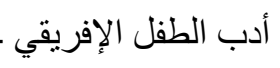

المناطق جنوب الصحراء، أما عن الأمية فلقارة إفريقيا نصيب الأسد منها، حيث تصل نسبتها في بعض الدول إلى (\%0\%)، كما هو الحال في بوركينا فاسو، و(س\%\%) في جنوب السودان، و( (\%) في النيجر، وكنتيجة طبيعية للفقر فالأفارقة يعانون من العديد من الأمر اض أهمها: النوم، وسوء التخذية، و الحصبة، والسل والتهاب الجهاز التنفسي، والإيدز، و الإسهال)؛ نتيجة نقص المياه وعدم وجود صرف صحي، ويقدر ضحاياها كل عام بالملايين، أما عن البطالة فهي مرتفعة جدَّا بالقارة لتصل في بعض الدول إلى (7٪\%)، كما

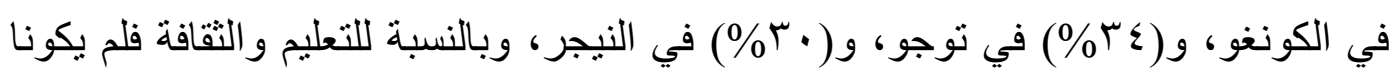
أحسن حظًا عن باقي المجالات الأخرى، حيث واجهت دول القارة السمر اء أزمة تعليم حادة استطاعت تقويض النمو الاقتصادي و الاجتماعي والثقافي بها، مما أدى إلى نقص البد العاملة الماهرة والقارئ الجيد والمفكر المستنير، نتيجة لقلة فرص التعليم المتاحة والعزوف عن التعليم وارتفاع معدلات التسرب من التعليم، فعادة لا يصل سوى ثلث الأطفال المتقدمين للتعليم إلى المرحلة الثانوية، كما أن واحدًا فقط من كل عشرة طلاب هو من يصل إلى الجامعة، وعادة ما ينتقل ثلثا الخريجين إلى العمل في إحدى الدول المتقدمة الأخرى خارج

$$
\text { القارة، سواء كانت أوربية أو آسيوية. }
$$

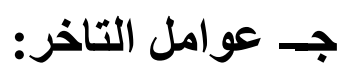

لعل هذا التدني وذلك التراجع في كافة المجالات سواء الاقتصادية أو الاجتماعية أو الثقافية بالقارة السمر اء، يرجع إلى ظهور النزعة الاستعمارية للأوربيين البيض واستخدامهم للأفارقة كالحطب في موقد بناء حضارة الغرب، بداية باستعمار بلادهم، مرورًا بانتزاع ثرو اتهم الطبيعية، نهاية باقتياد أهلها مكبلين بالقيود ومكدسين أكوامًا في أقبية السفن المتجهة إلى العالم الجديد في الأمريكيتين، فيما يُسمى بتجارة الرقيق، ولو أن الدراسة ترى أنه قد يجانب وجهة النظر هذه الصواب بعض الثيء، إلا أنه فيما يخص الثعوب و إرثها الحضاري لا تطلق الأحكام هكذا على عمومها، وللأسف حتى بعد حصول معظم الدول الإفريقية على استقلالها وتحرر ها من الاستعمار مع بداية النصف الثاني من القرن العثرين نتيجة للمد الثوري من القاهرة إلى كيب تاونن انطلاقًا من ثورة الضباط الأحرار في مصر عام 90 1 ، انتقل الحكم في معظم الدول الإفريقية إلى عددٍ من الأنظمة الوطنية الاستبدادية الفاسدة التي لم تراع إلا مصالحها دون النظر لمصلحة المواطن الإفريقي البسيط، وحل مشكلاته الأساسية، سواء الاقتصادية، أوالتعليمية، أوالصحية، وتحقيق طموحاته في عيش 


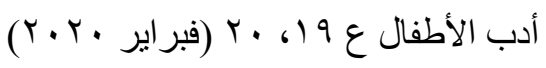
أدب الطفل الإفريقي

حياةٍ كريمة، وسدّ حاجاته الأساسية التي كان بعتقد أن افتقاده لها يرجع إلى الاستعمار وسياساته، إلا أنه اكتثف إبقاء الوضع كما كان عليه رغم رحيل الاستعمار من انخفاض متوسط دخل الفرد إلى تدهور الحالة الصحية و التعليمية و التقافية.

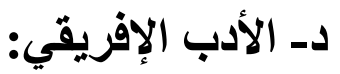

و لأن الأدب هو أحد صور التراكم الحضاري للأمم، ومر آة تعكس التراث الإنساني بتجلياته المختلفة، كان على الدراسة أن ثُلقي الضوء على الوجه الأبيض للقارة السمر اء وهو الأدب الإفريقي، سواء للكبار أو الصغار، وتُعرّف بعض الدراسات المتخصصة الأدب الإفريقي بأنه الأدب الوليد في البيئة الإفريقية، ومن أبناء هذه القارة أنفسهم معبرًا عن مشاعر هم و انفعالاتهم، مؤثرًا في القارئُ و السامع و المشاهد بأسلوبٍ رفيع. و ون وحدة الثقافة الإفريقية يرى (كلايف فريك) أحد المتفرقين الإنجليز"أن ثمة حقيقة هامة لا بد أن نضعها في الاعتبار، وهي وحدة الثقافة الإفريقية الحديثة، حيث إنها وحدة تكثف عن الثورة السياسية والاجتماعية، كما أنها هي التي ألهمت الأدب الإفريقي الحديث". و عن استخدام الاستعمار للنقافة والأدب كأحد أساليب تثبيت أقدامه في المستعمرات الإفريقية، تؤكد إحدى الدر اسات المتخصصة أن الاستعمار قد سعى جاهدًا إلى تغريب الأدب الإفريقي سواء للكبار أو الصغار عن المنطقة العربية، والترويج لمفهوم تقسيم إفريقيا إلى دول شمال إفريقيا البيضاء ودول جنوب الصحر اء الكبرى السوداء، و إمعانًا في التغريب فقد استبدل الاستعمار اللغة العربية إلى لغة الهوسا، في حين كانت الآداب العربية نَثِطة فيما يقارب ست عشرة دولة من دول الغرب الإفريقي إلى وقت قريب، ولو أن الدراسة الحالية ترى أنه إذا كانت الدول الاستعمارية ومفكروها خلال حقبة طويلة من الزمن قد استطاعوا فصل شمال القارة عن جنوبها وفرقوا بين الأفارقة شمال الصحر اء الكبرى وجنوبها، فإننا نستخدم هنا كلمة "إفريقيا" بالمعنى الجغر افي العام الذي لا يفرق بين منطقة وأخرى، أو بين جنسٍ وجنس، أو بين لونٍ ولون. وعن علاقة الأدب العربي بالأدب الإفريقي، ترى إحدى الدراسات أن خلو تاريخ الأدب العربي من إسهامات الأدباء الأفارقة السود جنوب الصحر اء الكبرى، يُعد ثغرة كبيرة في البناء الإفريقي، إذ فَقدَ بذلك جزءًا غاليًَا من مكتسباته الثمينة، فالذي يؤرخ لهذا الأدب لا يستطيع أن بقدم تاريخًا شاملً ومتكاملً له يغطي المساحة الجغر افية التي غطاها بالفعل عبر التاريخ. 


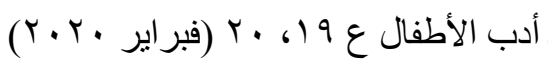
أدب الطفل الإفريقي - n - n

وفي نفس السياق، تشير در اسة أخرى إلى أن الأدب الإفريقي ظل قرونًا يعتمد على ألى الاتصـال الثفهي، ولم يدوَّن منه إلا القليل، مما يمكن اعتباره أنه أدب حديث العهد.

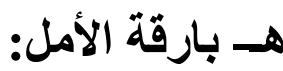

و لأن نـو اميس الكـون تقضــي بـأن الظلمــة يعقبهـا ضـياء الفجـر ، وإثــر اقة الصـبح و استرسال خيوط الضو ء، وحيث إنه من سُنّة الله في أرضـه أيضًا ألا تتفق النتائج دائمًا مـع مقدماتها، فعلى الرغم من المشكلات العديدة التي واجهت القارة السـر اء و الظروف الصسبة التي عاثـها سكانها على مدار تاريخهم الطويل نتيجة للسياسـة الاستعمارية بعد الاحتلال ثم نتيجة لممارسات بعض الأنظمة الدكتاتورية الفاسدة التي حكمتهم بعد التحرر من الاستعمار، فقد كانت تظهر بين الحين والآخر العديد من المحاو لات والإرهاصات الجادة من الأفارقة في كافة المجالات، وقد أثمر ذلك عن نجاح العديد من ساساتها و علمائها ومثقفيها بعدالعمل الجاد للوصول إلى مر احل الإبداع، مما أهلّهم لحصند الجوائز العالمية، و على ر أسـها جـائزة نوبل، حيث حصلو ا على ما يقرب من إحدى عشرة جائزة نوبل في الخمسين سنة الأخيرة فقط، خمس منهـا في السـلام، وو احدة في الطب، وأخرى في الكيميـاء، للعـالم المصـري (أحمد

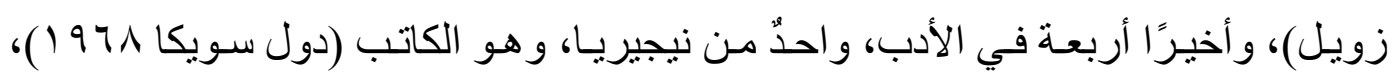
و آخر من مصر ، وهو الأديب المصري الكبير (نجيب محفوظ 911 ()، و اثنـان من جنوب

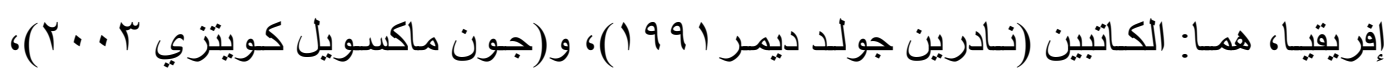
وللإنصـاف، لا يستطيع أحدٌ أن ينكر حجم العنايـة والاهتمـام اللذين أولتهمـا بعض الهيئات و المؤسسـات الثقافيـة الغربيـة، خاصـة الفرنسية، بحملة الثقافة الغربيـة مـن الأدبـاء و الكتـاب و المثقفين الأفارفة، بدايـةً مـن تقديم التسـهيلات لهم في مجـال التعريف بهم، مـرورًا بنشـر أعمالهم الأدبية، نهايةً بتقديم عناية خاصة للمبدعين منهم، حتى إن شـاعر إفريقيا المعروف (سيدار سنجور) قد حظي بشرف الانضمام إلى عضوية الأكاديميـة الفرنسية للتقافة، وهو شرفُ لا يصل إليه من الفرنسيين أنفسهم إلا الصفوة، وجدير بالذكر أن هذا التقدير لـم يأت من فر اغ، بل نتيجة لما أسهح به الثـاعر الإفريقي من جهدٍ في توطيد أركان اللغنة الفرنسية

$$
\text { في دول غرب إفريقيا. }
$$

ويلاحظ أن القارة السمراء قد أنتجت خلال عقودها الطويلة في مرحلة الاستعمار وما بعد الاستعمار ، عددًا من الكُتّاب والأدباء و المبدعين، الذين يستحقون الإشـادة بهم، أمثنال (تثينوا أتثيبي)، وهو روائي نيجيري، ومن أبرز أعماله الثناثية، و(وول سويانكا)، وهو 


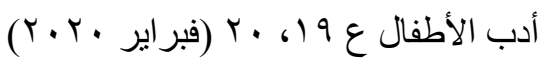
أدب الطفل الإفريقي

نيجيري أيضًا، ويُعد أفضل كُتّاب المسرح الإفريقي، ومن أبرز أعماله (محاكمة الأخ عام • 97 ( )، و (الموت وفارس الملك عام 9 ( ) )، و الكاتبة و الروائية السنغالية (ميريمابا)، وقد صدر لها أول رواياتها بعنوان (خطاب طويل جدَّا)، و(نشيد الأرجوان عام (919)، و الكاتب والروائي المصري الكبير (نجيب محفوظ) الذي حصل على جائزة نوبل في الأدب عام (911 (1) عن أعماله: (الثلاثية، والحر افيش، وأولاد حارتنا)، والكاتب الكيني (نجوجو و اتينجو)، في الرواية والمسرح والقصة القصيرة، والذي حصل على جائزة لوتس في الأدب، وكان دائمًا اسمه على رأس قائمة المرشحين لجائزة نوبل في الأدب كل عام وأهم أعماله المسرحية (الناسك الأسود)، والكاتبة الجنوب إفريقية (نادرين جولد مير) التي حصلت على جائزة نوبل في الأدب عام (199 (1)، عن أعمالها الأدبية في مناهضة الفصل العنصري في جنوب إفريقيا، رغم أنها ولِدت في أسرة برجوازية، وأخيرًا الكاتب الروائي الجنوب إفريقي (جون كويتزي) الذي حصل على جائزة نوبل في الأدب (ب . . ץ).

\section{و- أدب الطقل في المملكة المغربية:}

ونظرًا لقلة الدراسات التي تناولت أدب الطفل الإفريقي في دول إفريقيا بشكلٍ عام، وفي دول إفريقيا السمر اء جنوب الصحر اء الكبرى بشكلٍ خاص، فقد رأت الدر اسة أن تتناول أدب الطفل في إحدى دول الثمال الإفريقي البيضاء وهي المملكة المغربية كنموذجٍٍ لأدب الطفل الإفريقي، باعتبار ها أحد أهم المر اكز الثقافية بإفريقيا منذ عهدٍ بعيدٍ، الأمر الذي يمكن أن يلقي الضوء على شكل ومضمون و إثكاليات أدب الطفل الإفريقي. هذا وقد اقتصرت الدراسة على أربعة فصول: الفصل الأول منها بعنوان: الإطار المنهجي للار اسة، والفصل الثاني بعنوان: قارة إفريقيا .. القارة السمراء، وقد تناول بدايةً أصل اسمها وناريخها وجغر افيتها، مرورًا بأهم لغاتها و أديانها وحضارتها، نهايةً بالأحوال السياسية والاقتصادية والاجتماعية والثقافية، أما الفصل الثالث فهو بعنوان: الأدب الإفريقي،

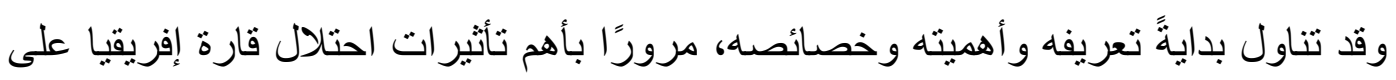
الأدب، نهايةً بمحتوى الأدب الإفريقي وأهم إثكالياته وسبل حل تللك الإشكاليات، وأخيرًا

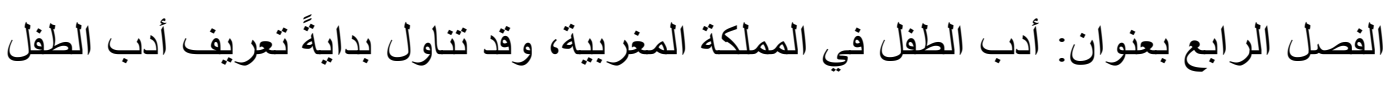
المغربي وتاريخه و أهدافه وخصائصه، مرورًا بواقعه و أهم أنواعه، نهايةً بأهم إثكالياته 


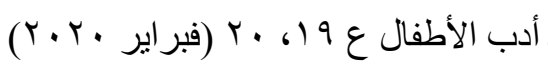

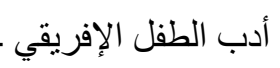

وقد انتهت الدر اسة إلى عددٍ من التوصيات التي تأمل الأخذ بها، مما قد يساعد على

وضع حلولٍ لأهم المشكلات التي تواجه أدب الطفل في قارة إفريقيا. و أخيرًا، لا أدعي أنني قد بلغت الغاية، فحسبي أنني قد عملت واجتهدت، فالكمال لله

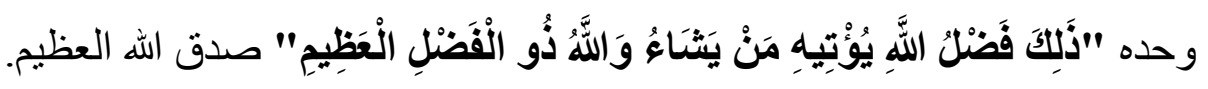
الفصل الأول: الإطار المنهجي للاراسة: أولاًَ المقدمة:

لا شك أن المملكة المغربية تمثل أحد أهم المر اكز الثقافية على مستوى كلِّ من الدول العربية والإفريقية منذ عهدٍ بعيد، حتى إنه من الممكن اعتبار الأدب المغربي نموذجًا مصغرًا للأدب العربي والإفريقي معًا؛ وذللك لتشابه الظروف والمشكلات و المعاناة فيما بينهما، حتى إنه من خلال دراسة أدب الطفل المغربي يمكن التعرف على خصائص و أنواع و أهم إثكاليات أدب الطفل في كلٍٍ من الدول العربية والأفريفية أيضًا، ولعل ذلك هو سبب ديب اختيار الباحث لموضوع الدراسة. ويؤكد ذلك الكاتب المغربي (العربي بن جلون)، ففي دراسة إحصائية له عن أدب الطفل المغربي، يذكر أن القلم المغربي في هذه الحقبة الثقافية الأدبية قد أفرز (ألف وخمسمائة وستة وخمسين) نتاجًا، ما بين قصةٍ ورواية ومسرحية وقصبدة شعرية ومعرفة ومجلة وجريدة للطفل، وقد احتلت القصة الدرجة الأولى بنسبة بح\%، تلتها المعارف بنسبة

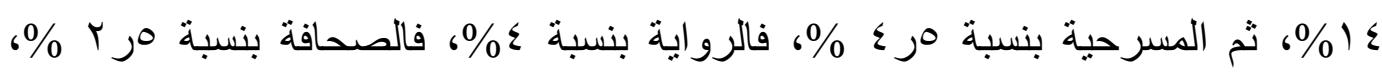
و أخيرًا يأتي الثعر بنسبة ب\%؛ ويضبف أنه إذا أحبينا أن نستقرئ القيم الكامنة في هذا النتاج الأدبي والثقافي، فسنجد على قمة السلم القيم التربوية بنسبة ؟ء\%، ثم القيم الدينية بنسبة ه ر 10 \%، ثم الاجتماعية بنسبة 9\%، ثم المعرفية بنسبة هر^\%، ثم التاريحية بنسبة

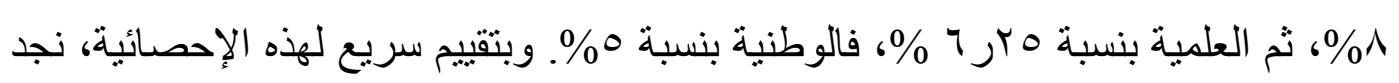
أن أن النسبة المئوية الأعلى هي للقصة، حيث أنها الجنس الأدبي الأثير لدى الطفل، بل هي الفن الساحر الذي يثحذ عقله ويسليه ويرفّه عنه، وينمي فيه القيم الإنسانية ويثري فيه حصيلته اللغوية، وهو ما لا يلقاه في غيرها من أشكال التعبير. ويتضح أيضًا من هذا التقييم أن نسبة القيم المعرفية والعلمية والفنية ضعيفة، في مئي حقبة يثهد العالم تطورًا ملحوظًا في مجال العلوم و الفنون و المعارف المتدفقة، ولا يخفى أن 


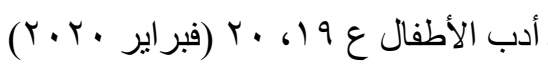
أدب الطفل الإفريقي

المعرفة في عصرنا الحاضر هي القوة، وحتى نخرج من شرنقة هذه المرحلة الصعبة، كان لا بد من قصّ بُدمَج بالخيال العلمي، دون أن ندير ظهورنا للمجالات الأخرى التي تسهم في تكوين شخصية الطفل، حتى يصبح عضوًا فاعلًا في مجتمعه. وتشير إحدى الدراسات إلى أنه بعد ازدهار أدب الطفل في المغرب على يد عددٍ كبيرٍٍ من الأدباء والكُتّاب المغاربة البارزين أمثنال: عبد السلام البقالي، ومحمد سعيد سوسان، ومحمد إبراهيم بغلو، و العربي بن جلون، الذين أنُروا المكتبة الأدبية، سواء المغربية أو العربية أو الإفريقية، بعددٍ هائلٍ من أشكال وصور أدب الطفل، نذكر منها على سبيل المثال: مجلات (سامي و العندليب والازدهار و الإرشاد... وغيرها)، فقد عرف أدب الطفل المغربي في السنوات الأخيرة تراجعًا ملحوظًا، سواء على مستوى الكتابة أو النشر أو الجودة أو القر اءة، مما يمكن تسميته بالأزمة ـ إن جاز التعبير ـ فكثيرٌ من الكُنَّاب و الأدباء المغاربة في أدب الطفل لم يَعْد لديهم اهتمام بمر اعاة خصوصية الكتابة للطفل لتحقيق الأهداف التربوية و الثقافية التي تسهم في بناء وتنمية جو انب شخصية الطفل، بقدر ما أصبح كل ما يههرم هو التهافت على النشر وترجمة القصص الأجنبية، دون مراعاة لخصوصية الطفل المغربي العربي الإفريقي.

وفي نفس السياق، ترى دراسة أخرى أن أدب الطفل في المغرب ما زال مُهمَّثًا بدرجةٍ كبيرة، مقارنةً بأدب الكبار ، خاصة و أن الدراسات حول أدب الطفل المغربي ماز الت قليلة نسيَّا، ومما يؤكد ذلك هو ندرة مر اجع أدب الطفل بالمغرب، ولعل ذلك يرجع إلى عدم اهتمام الدولة بالبحث بشكلٍ عام، وبالبحث الأدبي بشكلٍ خاص، وبالبحث في أدب الأطفال بشكلٍ أخص، وذللك كنتيجة طبيعية لتردي مستوى التعليم فيها. وعن مصادر أدب الطفل المغربي، ترى إحدى الدراسات أنه بمكن إرجاع أدب الطفل بالمغرب إلى ثلاثة منابع أساسية: أولها أدب المشرق العربي، خاصة من خلال كُنَّاب و أدباء مصر أمثال (على الجارم، وأحمد شوقي، وكامل كيلاني)، ثانيها الأدب العالمي خاصة الكُتَّاب أمثال (لافوتيه، وشار بيرو، وجيمس أري)، وأخيرًا التراث العربي و الإسلامي المشتق من قصص القران الكريم، وقصص جحا ونوادر أبي النواس وكتابات عبد الله بن المقفع، وقصص ألف ليلة وليلة. 


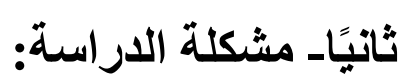

بعد فترة ازدهار طويلة لأدب الطفل المغربي على يد عددٍ كبيرٍ من الكُتَّب و الأدباء المغاربة البارزين الذين أثزروا المكتبة الأدبية، سواء المغربية أو العربية أو الإفريقية، بعددٍ

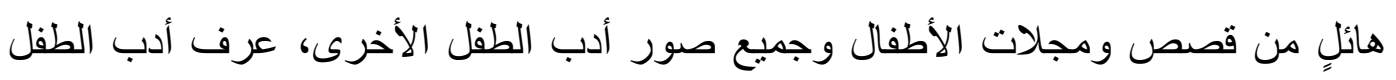

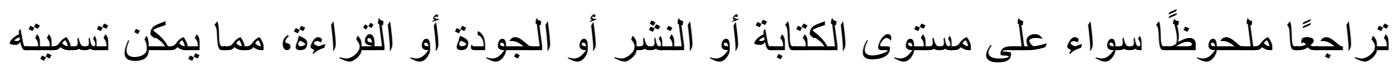

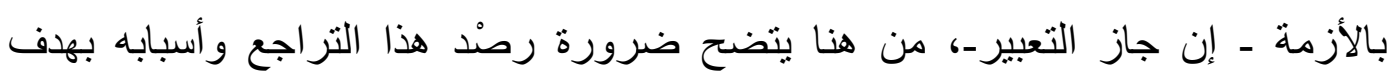

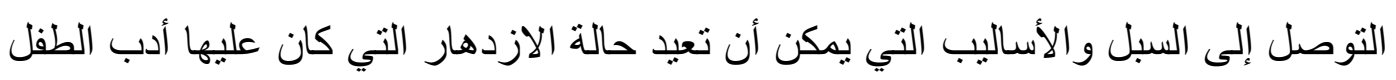

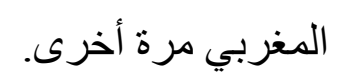

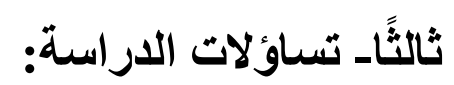

\section{حاولت الاراسة الإجابة عن التساؤلات التالية:}

$$
\text { ا ـ ما مفهوم أدب الطفل المغربي؟ }
$$

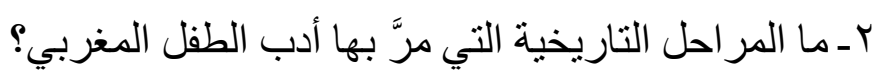

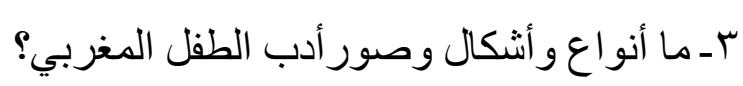

ع ـ ما أهم إنثكاليات أدب الطفل المغربي؟

ــ ما السبل و الوسائل التي يمكن أن تفيد في حل تللك الإشكاليات؟

$$
\text { رابعًا أهمية الدراسة: }
$$

1ـ أنها تعكس رأي أحد أهم رواد أدب الطفل الطف المغربي البارزين في أدب الطفل المغربي، وهو الكاتب (العربي بن جلون) بشكلٍ عام، وفي أهم إثكالياته وفي سبل ريل حلها دون تزيين أو تزييف أو تلوين.

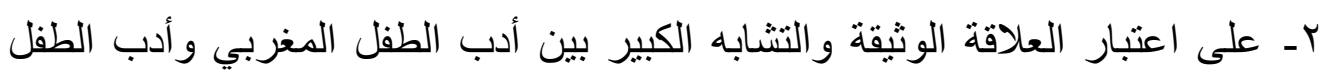
الإفريقي، فإنه يمكن التعرف على أدب الطفل الإفريقي بشكلٍ عام، وأهم إثكالياته وسبل حلها.

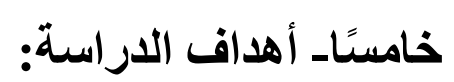
في ضوء ما سبق ذكره، فقد استهوفت ما يلي: 


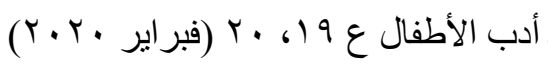

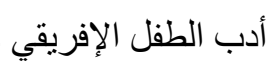

ا ـ التعرف على تاريخ أدب الطفل المغربي، وبالتالي تاريخ أدب الطفل الإفريقي.

r- التعرف على و اقع أدب الطفل المغربي، وبالتالي واقع أدب الطفل الإفريقي. "- التعرف على أهم إثكاليات أدب الطفل المغربي، وبالتالي على أهم إثكاليات أدب الطفل الإفريقي.

عـ التعرف على أهم السبل و الوسائل التي يمكن أن تسهم في حل أهم إثكاليات أدب الطفل المغربي، وبالتالي أدب الطفل الإفريقي.

\section{سادسًا- منهج الدراسة:}

استعانت الدراسة بالمنهج الوصفي التحليلي (Descriptive methods)؛ وذلك لتقديم صورة واضحة لو اقع أدب الطفل المغربي، سواء في الماضي أو الحاضر، وذلك لرصند أي تدهورٍ أو تراجعٍ قد وقع، إضافة للكثف عما إذا كان هناك علاقة بين هذا الواقع و التر اجع في أدب الطفل المغربي الحالي. سابعًا- مصطلحاث الدراسة:

حيث إن قيمة أي بحثٍ أو عملٍ علمي تعتمد على تحديد وضبط المصطلحات بشكلٍ دقيق، فقد كان علينا أن نوضح مصطلحات البحث، وهي على النحو التالي:

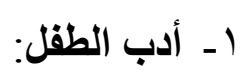

- الأصل اللغوي لكلمة الأدب مأخوذة من كلمة مأدبة في الطعام الذي يدعى إلبه الناس، ولذلك كان معناه اصطلاحًا، أنه يشمل التقيف والتهذيب في العقل و الشعور، فكما أن الطعام يغذي الأبدان فإن الأدب يغذي الوجدان. - ويعرف الأدب بثكلٍ عام بأنه فنٌّ من الفنون التي تصوّر الحياة (من كتاب النعمان الذي أرسل إلى كسرى عظيم الروم لدعوته للإسلام)، وتعرِّهه دراسة أخرى بأنه "كل ما أنتجه العقل الإنساني من دروب المعرفة وعلوم الأدب، لتشمل اللغة والصرف والاشتقاق و النحو و المعاني و البيان و البديع و العروض التص

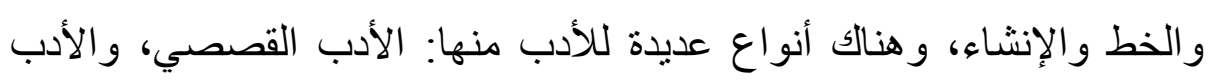
المقارن، أدب الرحلات، و الأدب الروائي... إلخ، وعرَّفه عمبد الأدب العربي الدكتور طه حسين بأنه "فن جميل يتوسل بلغة". 


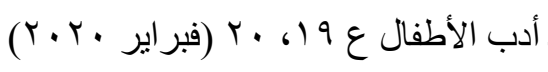
أدب الطفل الإفريقي

ويلاحظ أن أدب الطفل لم يتبلور في أدبنا الحديث إلا في العقود الأربعة الأخيرة من القرن العشرين، وذلك على الرغم من الإرهاصات الأولى لهذا اللون الأدبي، والتي تعود للقرن الحالي، و أدب الطفل كفنٍ متميزٍ لم يجد طريقه إلى الأدب العربي قبل أحمد شوقي في الشعر العربي، وقبل كامل كيلاني في القصة، وقبل ظهور مجلات الطفل المتخصصة، وقبل تخصص بعض الكُتّاب في أدب الطفل، ونظرًا لأن أدب الطفل هو عمل إبداعي بطبيعته، و هو في الوقت نفسه اختز ال للثقافات و المفاهيم والقيم والطموحات المستقبلية، فقد اختلف المهتمون بأدب الطفل في تحديد ماهيته ووصف طبيعته، فتعددت تعريفاته، وتتوعت مفاهيمه، وذلك على النحو التالي: - يعرّفه فريد جبر ائيل و آخرون بأنه "الكتب المُعدَّة للأطفال و التي يعدها خبر اء في أدب الطفل وتمتاز بجودة مادتها وأسلوبها، وملائمتها لذوق الأطفال ومستوى نضجهم. - ويعرّفه عمر محمود رضوان بأنه "الكلام الذي يحدث في نفوس الأطفال متعة

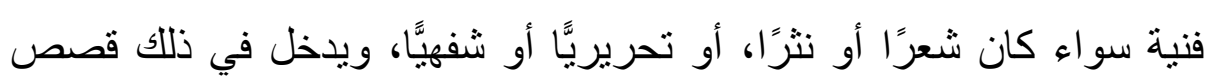
الأطفال وأناشيدهم ومسرحياتهم و أفلامهم. - ويعرفه محمد رشدي خاطر بأنه "كل ما يُقََّّم للأطفال من مادة مكتوبة، سواء كان كثبًا أو مجلاتٍ، وسو اء كان قصصًا أو تمثيلياتٍ أو مادة علمية. - وتعرّفه هدى قناوي بأنه "كل خبرةٍ لغوية ممتعة وسارة ذات شكلٍ فني، يمر بها الطفل ويتفاعل معها، فتساعده على إرهاف حسّه الفني، وتعمل على السمو بذوقه الأدبي ونموه المتكامل، وتسهح في بناء شخصيته وتحديد هويته وتعليمه فن الحياة.

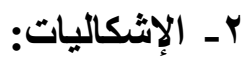

هي جمع إثكالية، وهي من المصطلحات الجديدة الو افدة على لغتنا العربية، وهي ترجمة لمصطلح (Problematic)، وقد شاع استخدامها مع منتصف السبعينيات من القرن العشرين، وهي مشتقة من فعل أشكل يشكل إشكال، وتعرفها بعض الدر اسات بأنها "منظومة من العلاقات تتسج داخل فكر معين العديد من المشاكل المترابطة، والتي لايمكن حلها بشكلٍ منفردٍ بل مجتمعة في إطار حلٍ شاملٍ لها جميعً"، و الإشكالية في معجم اللغة العربية المعاصر هي مجمو عة من المسائل التي تطرحها أحد فروع المعرفة، 


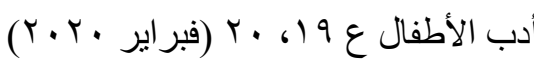
أدب الطفل الإفريقي

وهي تعني التباس اواشتباه في أمرٍ أو شيءٍ ما، مما يوجب التباس في الفهم، و الإشكالية في البحث العلمي هي طريقة تصورية يصو غها الباحث لمعالجة مسألة أو مشكلة معينة.

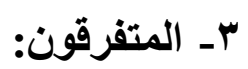

هو مصطلح تم استخدامه في الدراسة الحالية، ويُطلَق على الباحثين الغربيين الذين يهتمون بالثأن الإفريقي قياسًا على مصطلح المستشرقين الذي يُطلَق على الباحثين الغربيين الذين بهتمون بدر اسة أحو ال الثرق.

\section{الفصل الثاني: قارة إفريقيا .ـ القارة السمراء:

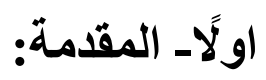

قارة إفريقيا، أو القارة السمراء كما يقال عنها، هي باختصـار شديد إحدى قار ات العالم القديم التي حباها الله بالعناصر الأساسية للحياة الكريمة من مساحة كبيرة من الأرض في موقعٍ متميزٍ بين قارات العالم الست، وباحتياطي ضخم من الموارد الطبيعية اللازمة للصناعة و الزر اعة، وبتربة شديدة الخصوبة، ومياه وفيرة من أمطار و أنهار وبحار ، و أخيرًا مناخ متنوع يجمع بين الحار و البارد و المعتدل، وقد كان طبيعيَّا أن يقطف سكانها ثمار ذلك كله، فيعيشون في رخاء ووئام، كما ينمتعون بمستوى عالٍ من الرفاهية ورغد العيش، إلا أن حظهم التَّعِ أن تعرضوا للغزو من المستعدرين الأوربيين البيض، حتى أتى عليهم حين من الدهر ليعانوا العسف وشتى صنوف القهر والإبادة والتمبيز العنصري الذي فرضه الاستعمار عليهم، ولكن نواميس الكون تقضي بأن الظلمة يعقبها دائمًا ضياء الفجر وإثر اقة الصبح واسترسال خيوط الضوء، فقد استطاعت إفريقيا تحطيم أغلالها وأن تعود لها الروح مرة أخرى لتشارك دول العالم المتقدّم في مسيرة التنمية. وقد حرصت الدراسة على تخصيص فصلٍ كاملٍ عن قارة إفريقيا؛ للتعرف عليها عن قرب قبل وأثناء وبعد الاحتلال، مما قد يساعد في التعرف على شكل ومحتوى وأهم إثناليات أدب الطفل الإفريقي.

\section{ثانيًاـ أصل كلمة إفريقيا:}

تشير إحدى الدراسات إلى أن اسم إفريقيا يرجع الثق الأول منه وهو (أفري) إلى الفنيقبين، و هو لفظ يعني لايهم (الغبار) وما زال يستخدم حتى الآن في اللغة العامية المصرية (عفر تعني غبار)، أما لفظ (كا) فيعني (أهل)، مما يعني أن إفريقيا هي أهل المنطقة المليئة 


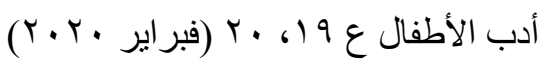
أدب الطفل الإفريقي

بالغبار (')، و ترى دراسة أخرى أن الثق الأول من إفريقيا وهو (أفري) يعني عند القبائل الأمازيغية كلمة (كهف)، أما الثق الثاني وهو (كا) فيعني (أهل)، أي أن إفريقيا تعني سكان الكهوف باللغة الأمازيغية، وتضيف نفس الدراسة أن ما حافظ على هذا الاسم هو إطلاقه على المماللك الإسلامية في تونس إفريقيا إبان القائد المسلم عقبة ابن نافع، وفي نفس السياق ترى دراسة ثالثة أن اسم إفريقيا باللغة اليونانية يعني (أرض الرعب)، أما باللغة اللاتينية فيعني (الأرض المُشمسة شديدة الحرارة)(').

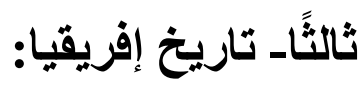

تشير إحدى الدر اسات المتخصصة إلى أن قارة إفريقيا مرَّت بعدة مر احل تاريخية هي: أـ العصر الحجري القديم: كانت القارة نشكّل مع قارات الأرض الأخرى قارة (بنجو انا)، كما كانت بها حيو اناتُ ضخمة كالديناصور ات، ثم جاءت الحقبة الوسيطة (منذ مائة وخمسين مليون عام)، حيث انفصلت القارة عن جزيرة مدغشقر وأصبحت ملاحقة لقارة (جوندو انان).

بـ العصر الطباشيري: انفصلت قارة إفريقيا عن قارة أمريكا الجنوبية. ج- عصر ما قبل التاريخ: تعتبر قارة إفريقيا من أقدم القارات التي كانت مأهولة بالسكان، حيث سكنها الإنسان منذ ما يقرب من سبعة ملايين عام، ومع انتهاء العصر الجليدي تحولت الصحر اء إلى مناطق يمكن العيش بها، وقبل ... .0 عام قبل الميلاد أصبحت أرض القارة صحر اء جافة، مما دعا السكان للهجرة إلى نهر النيل وتكوين المجتمعات الدائمة، وكان معظم السكان يعملون في الزر اعة وتربية

الحيو انات و الصيد، ومع بداية الألفية الأولى فبل الميلاد عمل السكان في الحدادة. د- عصر أوائل الحضارات: بدأ العصر الأول في عام ..بس قبل الميلاد، وثركزت هذه الحضار ات في شمال إفريقيا مثل الحضارة الفرعونية، ثم بدأت الاستكثافات الأوربية لقارة إفريقيا، وذلك عن طريق الحضارة اليونانية والرومانية، وفي عام (rTr) قبل الميلاد قام الإسكندر الأكبر بتأسيس مصر وتحرير ها من الاستعمار الفارسي الذي ازدهر حكمه وأسس دولة البطالمة، حتى أصبحت مصر تابعة للإمبر اطورية الرومانية، وفي القرن السابع الميلادي وصلت الخلافة الإسلامية إلى مشارف إفريقيا و أصبحت تابعة لها("). 


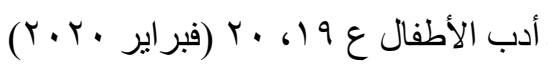

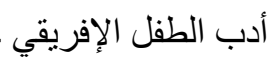

هـ - إفريقيا قبل الاستعمار: وعن علاقة الاستعمار بإفريقيا ترى دراسة أخرى أن إفريقيا في فترة ما قبل الاستعمار كانت تتضمن العديد من الدول و الحكومات وصل عددها إلى عشرة آلاف دولة وحكومة نظامية، وكانت تتكون هذه الأنظمة دن مجموعاتٍ من العائلات لكل منها لغتها الخاصة، وتُعد (أيف) تاريخيَّا هي أولى دول أو ممالك (اليوربا)، وقد تأسست حكوماتها تحت قيادة (أوبا المقد)، حيث أصبحت أحد المراكز الثقافية والدينية الكبرى في إفريقيا، وقد اشتهرت بنحت وتشكيل البرونز، و هو تقليد طبيعي فريد في ذلك الوقت، أما المرابطون فهم إحدى سلالات الأمازيغ الحاكمة في الصحر اء، وقد بلغ انتشار ها على نطاقٍ واسعٍ في شمال غرب إفريقيا، ويُعد (بنو هلال وبنو معقل) جماعة من قبائل العرب البدو من شبه الجزيرة العربية الذين هاجروا غربًا عبر مصر في القرن الثالث عثر، مما أحدث اندماجًا بين الأمازيغ و العرب وانتشار الحضارة العربية. و- تجارة الرقيق في إفريقيا: وتضيف نفس الدراسة أن الكثير من دول إفريقيا كانت تعتمد في اقتصادها على تجارة الرقيق، وقد ارتفعت معدلاتها كغير ها من المناطق

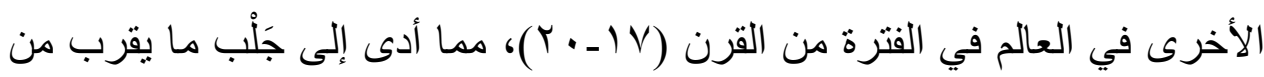
ثمانية عشر مليون إفريقي عبر الصحراء والمحيط الهندي إلى العالم الجديد، إلا أن هذا المعدل قد انخفض تدريجيَّا عبر الأطلنطي؛ بسبب صدور القوانين المناهضة للرق في أوربا وأمريكا وانتنار البحرية البريطانية قبالة سواحل إفريقيا الغربية لمنع التجارة، الأمر الذي أدى إلى اتجاه الدول الإفريقية إلى تجاراتٍ أخرى في

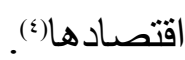
ز- الاستعمار الأوربي في إفريقيا: وثرى در اسة أخرى أن في أواخر القرن التاسع عشر اشتركت جميع الدول الاستعمارية في حملة تزاحم كبرى، وقامت في عام ( ع (1 (1) باحتلال معظم الدول الإفريقية وتحويلها إلى مستعمر اتٍ لها، ولم يتركوا سوى دولتين فقط هما: ليبيريا لوجود جاليات أمريكية كبيرة بها، وإثيوبيا المسيحية الأرثوذكسية (الحبشة)، وقد استمر الحكم الاستعماري الغربي لإفريقيا حتي نهاية الحرب العالمية الثانية. ح- استقلال الاول الإفريقية: عقب انتهاء الحرب العالمية الثانية بدأت معظم الدول الإفريقية تثور للحصول على حريتها، حتى تحقق ذلك لجميع الدول الإفريقية، ففي 


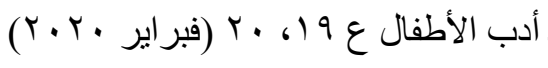

أدب الطفل الإفريقي

عام (1901) حصلت ليبيا على استقلالها من الاستعمار الإيطالي، وفي عام (1907) حصلت كل من نونس والمغرب على استقلالها من الاحتلال الفرنسي، وفي نفس العام حصلت السودان على استقلالها من الاستعمار البريطاني، وتبعتها غانا في العام التالي لتصبح أول مستعدرة من جنوب الصحر اء الكبرى في إفريقيا تحصل على استقلالها، ثم توالت حركات التحرر من الاستعمار لباقي الدول الإفريقية في العقد التالي، وبشكلٍ عام حصلت معظم الدول الإفريقية على استقلالها عن طريق الوسائل السلمية فيما عدا الجزائر ومصر، و على الرغم من أن دولة مثل جنوب إفريقيا كانت من أوائل الدول التي حصلت على استقلالها، فإنها أصبحت تحت حكم المستوطنين البيض حتى عام ( 99 ( ))، وتم إنهاء حكمه بناء على اتفاقية الفصل العنصري.

طـ إفريقيا عقب التحرر من الاستعمار: أصبحت قارة إفريقيا تضم ؟0 دولة مستقلة ذات سيادة، ور غم تحرر ها فإنها ما زالت تعاني من عدم الاستقر ار و الفساد و العنف و الصر اعات الداخلية والحروب الأهلية، فمعظم الدول التي تحكم في إفريقيا هي أنظمة جمهورية إلا أن القليل منها يطبق الديموقر اطية، وقد لعبت الحرب الباردة بين أمريكا والاتحاد السوفيتي سابقًا وكذلك سياسات صندوق النقد الدولي، دورًا كبيرًا في عدم استقرار الدول الإفريقية وعدم توحدهم، حيث كان هناك بعض الدول الإفريقية تدور في فلك الكتلة الشرقية، وأخرى في فلك الكتلة الغربية، الأمر الذي أدى إلى نشوب صر اعاتٍ بينهما بالوكالة)(ه).

\section{رابعًا- جغر افية إفريقيا:}

تشير إحدى الدراسات المتخصصة أن قارة إفريقيا هي الجزء الأكبر ضمن النتوءات

$$
\text { الجنوبية الثلاث الكبرى لليابسة في الكرة الأرضية. }
$$

أـ الموقع: يفصلها البحر المتوسط عن قارة أوربا، وترتبط بقارة آسيا عن طريق برزخ قناة السويس، وحدودها في أقصى نقطة في الثمال هي رأس بن السقى في تونس إلى أقصى نقطة في الجنوب كيب أجوالس في جنوب إفريقيا، وفي رأس هافون في الصومال بالثرق إلى كيب فرد بالغرب بمدغشقر. 


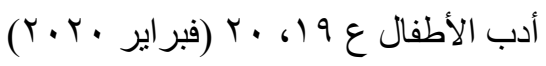

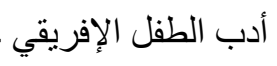

بـ المناخ: يجمع بين عدة أقاليم مناخية، هي: الإقليم الاستو ائي في المناطق القريبة من خط الاستو اء، و الإقليم الصحر اوي ويتمثل في صحاري كلهاري و الصحر اء الكبرى وصحر اء نامبيا، والإقليم الموسمي ويتمثل في هضبة إثيوبيا (الحبشة)، و إقليم البحر المتوسط ويتمثل في الساحل الشمالي للقارة، تغطي المناطق الوسطى و الجنوبية منه حشائش السافانا والغابات المطيرة التي تنمو في الأحراش الكثثفة، مما أدى إلى وجود مجمو عة كبيرة من الحيوانات آكلة اللحوم و الأعشاب. ج- الأقاليم الجغرافية: تضم قارة إفريقيا خمسة أقاليم جغر افية، هي: الإقليم الثمالي ويضم (الجزائر، وليبيا، وموريتانيا، ومصر، و المغرب، وتونس)، و الإقليم الجنوبي ويضم (أنغولا، جنوب إفريقيا، نامبيا، موزمبيق، زامبيا، بوتسوانا، زيمبابوي، مالوي، ليسوتو، سوازيلاند)، و الإقليم الثرقي ويضم (السودان، و إثيوبيا، وتنز انيا، وجنوب السودان، والصومال، ومدغشقر، وكينيا، و أوغندا، و إرتريا، ورواندا، وجيبوتي، وجزر القمر، وموريشيوس، وغينيا بيساو)، والإقليم الغربي ويضم (مالي، و النيجر، ونيجيريا، وبوركينافاسو، وساحل العاج، و غانا، و غينيا، و السنغال، وبنين، وليبريا، وسير اليون، وتوجو، و غينيا بيساو، و غامبيا، و الرأس الأخضر)،

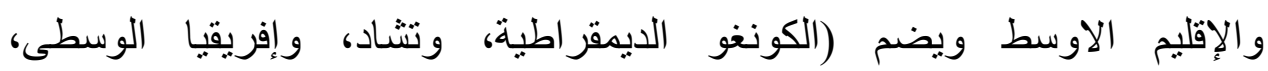
و الكاميرون، و الكونغو برازفيل، و الجابون، وغينيا الاستوائية، وبوروندي، وسأو تومي). دـ مميزات عامة: تتميز قارة إفريقيا ببعض المميزات عن القار ات الأخرى، أهمها أنها تأخذ شكل المثلث يتسع في الثمال ويضيق في الجنوب، تُشرف على ممرات عديدة، تتحكم في التجارة الدولية مثل: قناة السويس، ومضيق باب المندب، ومضيق جبل طارق، مساحتها • ب مليون كم، بنسبة ج\% من مساحة الكرةالأرضية، ( 0ب\%) من مساحة اليابسة، و القوة البشرية لديها (1) (Y) مليار نسمة، هي الثانية بعد قارة آسيا، وقد أثبتت الأبحاث أن قارة إفريقيا موطن الإنسان الأول الذي قام بالانتقال إلى

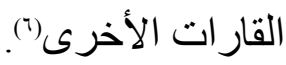




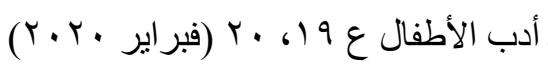

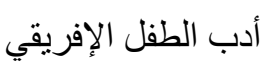

\section{خامسًا أهم لغات القارة: - مات}

تشير بعض الدراسات المتخصصة إلى وجود أكثر من ألفي لغة يتم التحدث بها

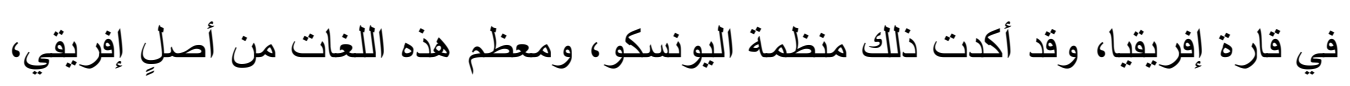

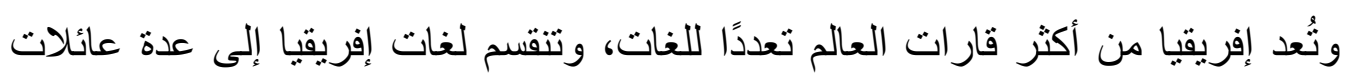

$$
\text { لغوية: أهمها: }
$$

- العائلة النيلية الصحراوية: وتتألف من أكثر من مائة لغة، يتحدث بها ـ مليون

نسمة من تشاد و إثيو بيا وكينيا و السودان و أو غندا وتنز انيا.

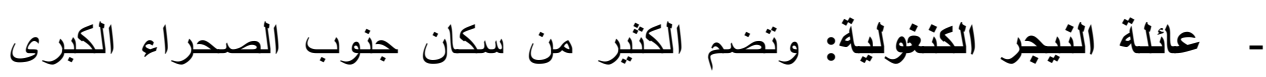

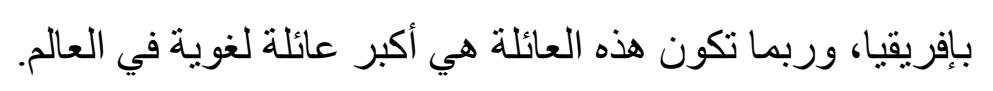

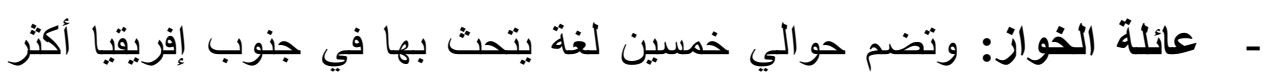

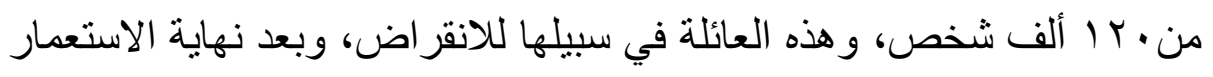

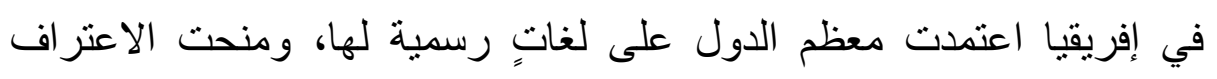

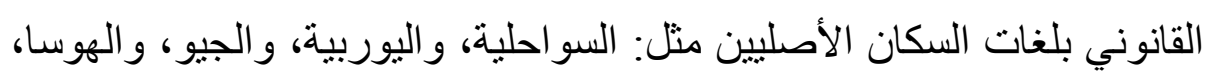

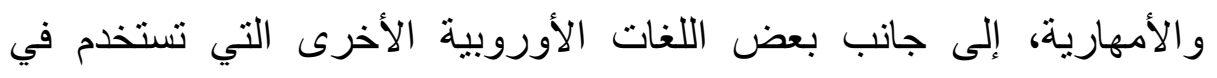

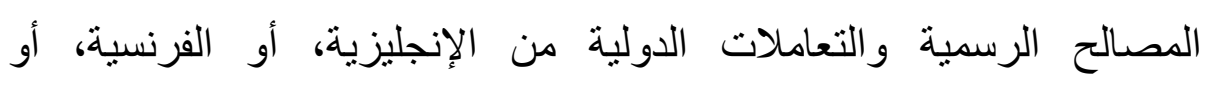

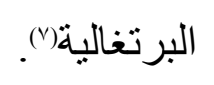

\section{سادسًا أهم أديان القارة:}

ترى إحدى الدراسات أن الثعوب الإفريقية مندينة بطبيعتها، ويعتنقون الكثير من

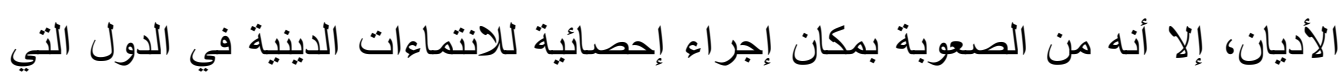

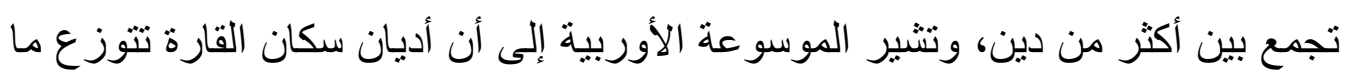

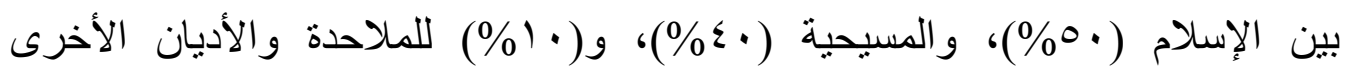
الصغيرة:(م).

$$
\text { سابعًا- أهم حضار الهات القارة: }
$$

تثبر إحدى الدراسات المتخصصة إلى أن قارة إفريقيا تمتاز بتاريخها الطويل

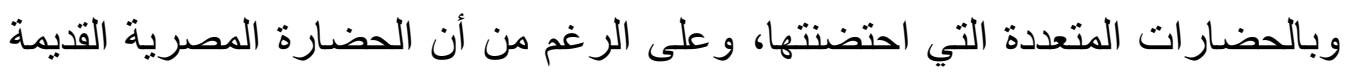

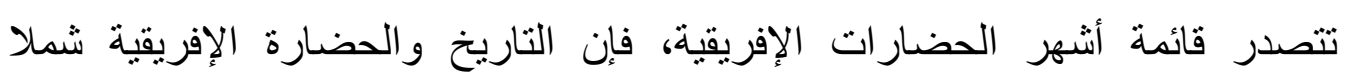




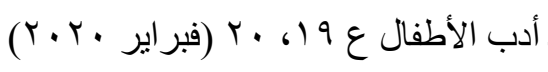
أدب الطفل الإفريقي - n - n

مجمو عة ممالك و إمبر اطوريات أخرى نشأت إلى جانب الحضارة المصرية، وذلك كما يلي:

أـ الحضارة الفرعونية القديمة: تُعد من أقدم و أطول الحضار ات بقاءً، حيث أثرت تأثثرًا كبيرًا على المناطق المجاورة لها غربًا إلى ليبيا، حتى وصلت شمالَا إلى جزيرة كريت وجنوبًا إلى مملكة أكسوم، كما عقدا العديد من الصفقات التجارية مع الفينيقيين في الساحل الثمالي لإفريقيا (قرطاج)، و أيضًا مع بلاد بونت (الصو مال حاليًا) أثناء حكم الملكة الفر عونية حتشبسوت.

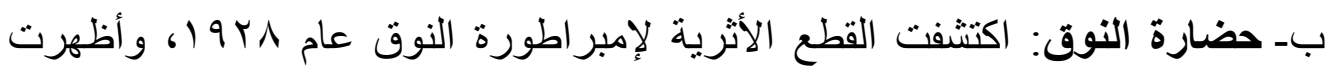
الأبحاث أنها حضارة معقدة في غرب إفريقيا، بدأت منذ عام . .9 ق.م، حتى . . . . . . موجة الجفاف وحدوث مجاعة قضت على سكانها. ج- إمبراطورية قرطاجة: تأسست قرطاجة القديمة على يد الفنيقيين عام ؟ ام ق.م، وقد غطت معظم شمال غرب إفريقيا، كما أبدعت في صناعة الأثاث والمنسوجات، ووضعت نظامًا إداريَّا للحكم. د- إمبراطوريةة سونغاي: من أهم و أكبر الإمبر اطوريات في العالم، حيث كانت نشغل مساحة كبيرة من الأراضي في غرب إفريقيا، استمرت في الفترة من القرن (10 ד 1 ) )، اعتمدت على تجارة الذهب. هـ إمبراطورية مالي: ازدهرت بين القرنين (س ا ـ ا ( ) على بد الملك (سونجاتا كيتا)، اعتمد اقتصادها على الملح والذهب والعاج، زاد نموها على يد الملك (منسا موسى) الذي أصبح أغنى رجال العالم، وكان أول زعيمٍ إفريقي أسود يؤدي فريضة الحج عبر

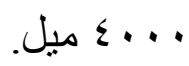

و- مملكة أكسوم: من أكبر الإمبر اطوريات الإفريقية (إثيوبيا حاليًا و الحبشة سابقًا)، تمتذ عبر شرق إفريقيا وجنوب مصر وخليج عدن، استمرت من عام ( . ( -. ؟) ميلاديَّا، قامت بالتجارة مع الهند وروما، اشتهرت بالأبر اج و الكنائس العالية(9). 


\section{ثامنًا الأحوال السياسية في قارة إفريقيا:}

تشير إحدى الدراسات إلى أن جميع نظم الحكم بإفريقيا قبل الاستعمار كانت ملكية، وبعد الاستعمار كان يتم الاستعانة بالملوك وأقاربهم في حكم الممالك، الأمر الذي أفاد الاستعمار في فهز طرق وأساليب الحكم وأُسس التعامل مع السكان، وقد اختلفت الأنظمة السياسية باختلاف الاستعمار، فبالنسبة للاستعمار الفرنسي فقد كان بتدخل في كل شيء في المستعمرات، سواء في الثقافة، أو نظام التعليم، وفي أنظمة العمل، و الصناعة، و الزر اعة، حتى إنه كان لا يُسمَح بتدريس اللغات المحلية في المدارس، وقصر التعليم على الفرنسية، كما كان يعتبر سكان المستعمرة مواطنين فرنسيين، أما الاستعمار الإنجليزي فكان لا يهتم بذلك معتبرًا أن الأفارقة لا يمكن أن يصبحوا إنجليز، وترك لهم الثقافة والتعليم والأنظمة الأخرى، وكان يهتم فقط بالاستيلاء على موارد المستعمرة الطبيعية؛ لتشغيل المصانع في لندن، وقد أسهمت كل طرق الاستعمار في إيجاد فجوة بين الاستعمار و السكان و القضاء على الثخصية الإفريقية، الأمر الذي أدى إلى ظهور الحركات الوطنية المطالبة بالاستقلال، وأن إفريقيا للإفريقيين، حتى حصلت جميع الدول الإفريقية على استقلالها في عام (•97 (1)، فيما عدا جنوب إفريقيا التي تحررت في العقود اللاحقة، وأصبحت أغلب الأنظمة الحاكمة بعد الاستعمار

$$
\text { جمهورية)('). }
$$

\section{تاسعًا- الأحوال الاقتصادية في قارة إفريقيا:}

تشير إحدى الدر اسات الاقتصادية إلى أن إفريقيا من أفقر قار ات العالم من حيث

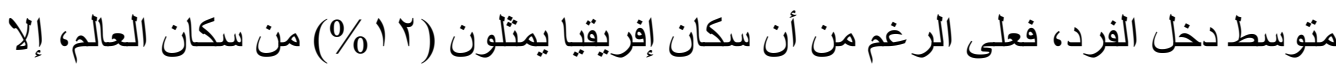
أن نصيب إفريقيا يمثل (r\%) من الدخل العالمي، وتُعد المواد الأولية من الحاصلات الزر اعية و المعادن النفيسة من الذهب و البلاتين و الكروم من أبرز ما تتتجه القارة، وتعتمد عليه في صادر اتها، حيث تمتلك إفريقيا (r (\%) من احتياطي النفط في العالم، و( • ع\%) من ذهب العالم أيضًا، و( •9\%) من البلاتين، وشهدت بعض دول إفريقيا أخيرًا ارتفاعًا

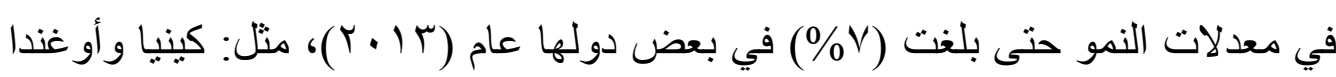
وتنز انيا، وتتضمن نيجيريا أكبر اقتصاديات القارة، تليها جنوب إفريقيا، ثم مصر، وقد دخل رأس المال العالمي أخيرًا للاستثمار في بعض الدول المستقرة سياسيَّا، مثل كينيا

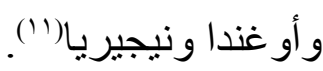




\section{عاشرًا - الأحوال الاجتماعية في قارة إفريقيا:}

ترى إحدى الدراسات أن قارة إفريقيا قد شهدت تحولاتٍ اجتماعية كبيرة خلال القرن الحالي، حيث تحولت المستعمرات التي رسم الأوربيون حدودها إلى دولٍ مستقلة، كما سنَّت

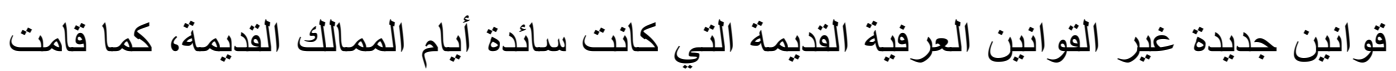
فيها الأسس البيروقراطية في الإدارة التي تخالف النمط الذي كان سائدًا في السلالات الاجتماعية السابقة، كما ظهرت المدن الحديثة والصناعات التحويلية، وأمسكت بإدارة البلاد

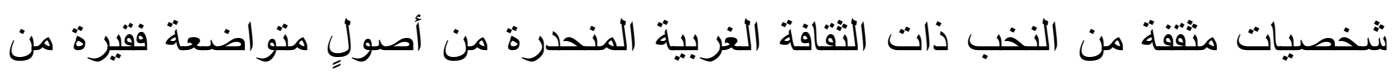

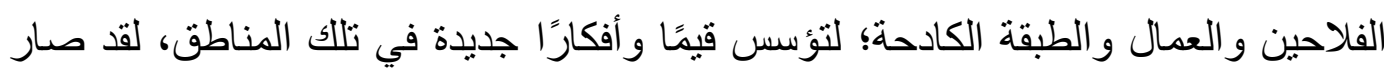

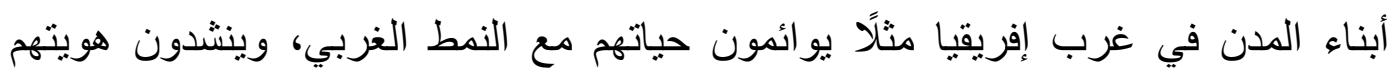

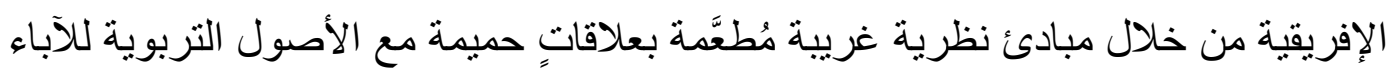

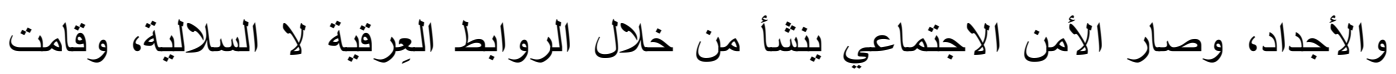

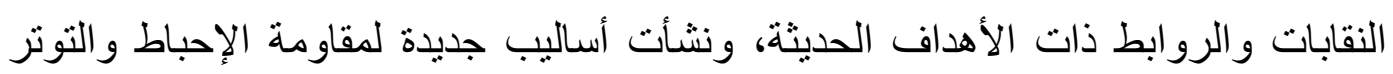

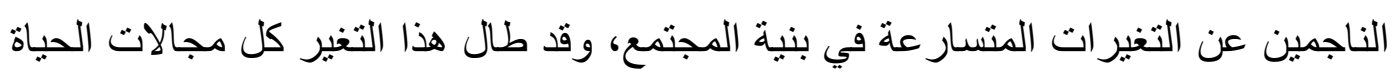

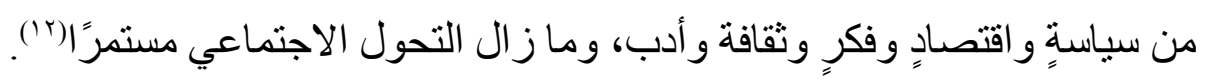

\section{حادى عشر- الثقافة والفنون في قارة إفريقيا:}

تثير إحدى الدراسات إلى أن هناك جوانب كبيرة من الثقافات الإفريقية التقليدية

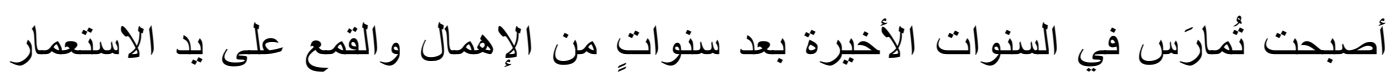

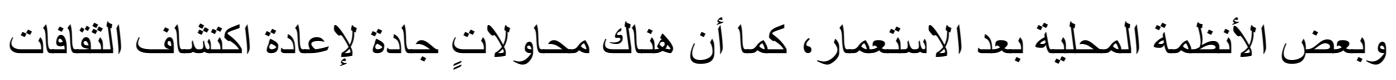

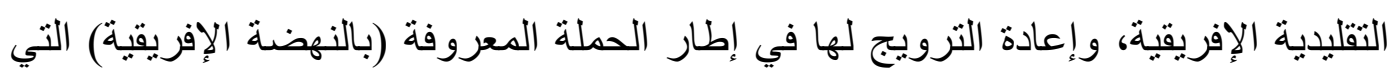

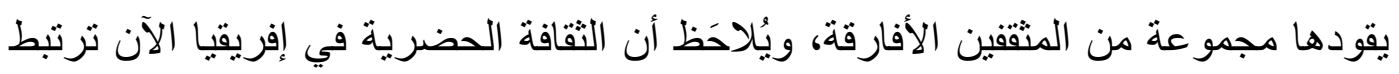

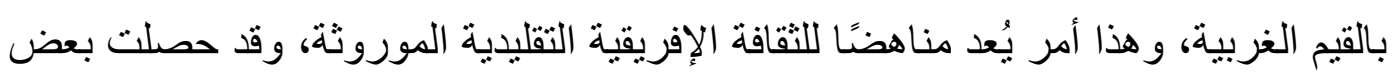

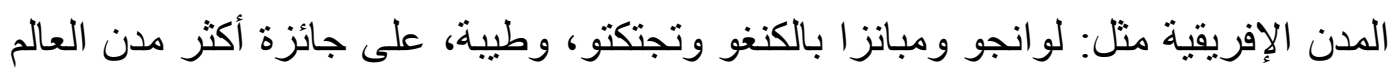

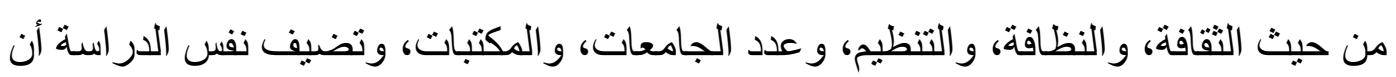

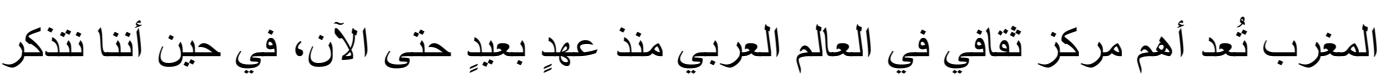

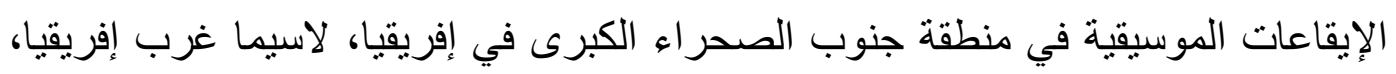
و التي تحولت عن طريق التجارة عبر الأطلسي إلى الأنواع الحديثة من الموسيقى، مثل:

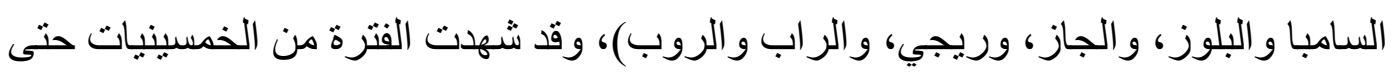




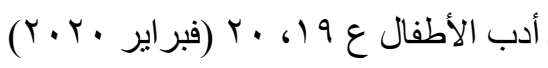
أدب الطفل الإفريقي

السبعينيات من القرن الماضي تجميعًا لهذه النوعية من الموسيقى ممزوجة بالطبول الإفريقية الثعبية المميزة، وموسيقى (الهايلايفو) التي تجمع بين الكورال الغنائي لجمهورية جنوب إفريقيا ونمط الإيقاع الراقص لجمهورية الكونغو الديموقراطية، وعادة ما يظهر تأثير الموسيقى العربية على دول شمال إفريقيا، بينما بظهر تأثير الموسيقى الغربية على دول

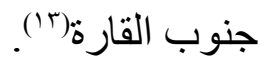

\section{الفصل الثالث: الأدب الإفريقي:

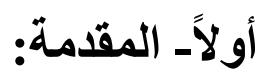

كان موضوع الأدب الإفريقي إلى عهٍٍ قريبٍ حكرًا على المتفرقين بثكلٍ خاص من أمريكا وأوربا، حتى ظهر على أبديهم مصطلح "الأدب الإفريقي"، إلا أن هذا المصطلح اختلط مع ظهوره بالنزعات الاستعمارية ومخلفاتها الثقافية، وتدرج في مجاله من الأدب الثعبي الفلكلوري غير المكتوب إلى الأدب المكتوب باللغات الأوربية الثناث التي دخلت في ركاب السيطرة الاستعمارية، وهي بترتيب ظهور ها في إفريقيا: البرتغالية، ثم الإنجليزية، ثم الفرنسية، ثم شمل أدب اللغات الإفريقية المكتوبة مثل السواحلية، و الزولو، والهوسا، ومع ذللك لم يسلم المصطلح من التحيز إلى أوربا و العطف على الأفارقة من منظور التلمذة على

إلا أن موجة التحرر والاستقلال التي اجتاحت القارة الإفريقية بداية من النصف

الثاني من القرن التاسع عشر، وتحرر أكثر من ثماني عشرة دولة من القاهرة شمالاً إلى له كيب تناون جنوبًا، ومن أنتاناريف (عاصمة مدغثقر) شرقًا إلى لواندا (عاصمة أنجو لا)غربًا، أدت إلى تغير اتٍ كثيرة في معاني المصطلح ودلالاته الثقافية، كما أدت إلى ظهور عددٍ كبيرٍ من الأدباء الأفارقة الجدد ليس في اللغات الأوربية الثلاث المذكورة فحسب، و إنما في اللغات المحلية الإفريقية المكتوبة أيضًا، حتى علا صوت الإبداع الأدبي بلغات المستعمرين، وأخذ في النمو والبروز مع ازدياد موجة التحرر و الاستقلال، مما شكَّل ظاهرة أدبية مثيرة للانتباه،

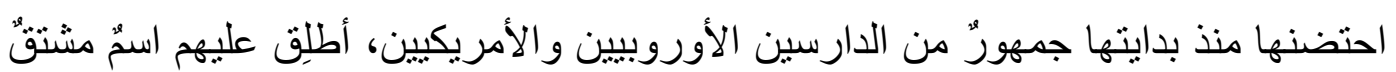
من طبيعة اهتمامهم وهو المتفرقين (African)، قياسًا على قول المستشرقيين الذين يهتمون 


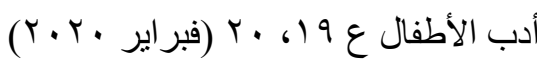

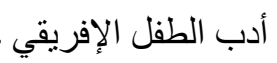

ولقد ترعرع الأدب الإفريقي في ظل الجدل الاستعماري حول تاريخية الإفريقيين، وبقيث ملامح التحدي والاحتجاج مرسومة على جبين الأديب و الكاتب الإفريقي، يخطب لإقناع قارئه، ويعرّفه بخطر دعاوى الاستعمار و عدم صلاحية فلسفته للمجتمع، وهو ما يعبر عنه الروائي النيجيري الكبير (تشينو أثنيبي) "سأكون جدّ سعيد إذا لم تُحدِث رواياتي أثرًا على القر اء سوى إقناعهم بأن ماضيهم لم يكن أبدًا سوى ليلًا طويلًا من الهوجية، أنقظه منها ـ لوجه الله - أول طارقٍ أوروبي". ثانيًا تعريف الأدب الإفريقي:

شغل الأدب الإفريقي الكثير من الكُتّاب والأدباء الأفارقة، وتثبر إحدى الدراسات إلى أن الأدب الإفريقي له العديد من التعريفات، فعرفه الأديب الجنوب إفريقي (مازيسي كونيتي) بأنه الأدب الذي يصوّر واقعًا إفريقيا بجميع أبعاده، بما في ذلك النزاع مع القوة المسيطرة على القارة، و النزاعات داخلها، سو اء كان الأديب من أصل إفريقي أو غيره، بينما عرّفه الثـاعر (كرستوفر أوكيحبو) بأنه الأدب الموجود داخل إفريقيا('). وترى دراسة أخرى أن جمهور المتفرقين قد أجمع على أن الأدب الإفريقي هو "أدب المناطق الواقعة جنوب الصحراء الكبرى"؛ وذلك لإجماعهم على أن الصحر اء الكبرى تقسم إفريقيا إلى قسمين: قسم في الثمال يضم الدول العربية الإسلامية البيضاء، وقسم في الجنوب من الصحر اء الكبرى يضم دول إفريقيا السوداء. ولعل أنسب التعريفات كانت هي الصادرة عن الروائي النيجيري (نتينو أتثيبي) الأدب الإفريقي هو "المجموع الكلي للآداب القومية و العِرقية في إفريقيا"(10)، وفي نفس السياق نرى دراسة أخرى أن الأدب الإفريقي هو "الأدب الوليد في البيئة الإفريقية ومن أبناء القارة أنفسهم، بعيدًا عن مشاعر هم وانفعالاتهم، مؤثرًا في القارئ و السامع بأسلوبٍٍ رفيع"(14). ثالثًاـ تاريخ الأدب الإفريقي: تشير بعض الدراسات إلى أن الأدب الإفريقي بدأ منذ ما يقرب من (11 + (Y) في مصر الإفريقية، حيث كان من أهم الثعائر الدينية للفر اعنة أن يُدفَن مع الموتى كتابُ يُسمى (كتاب الموت)، ويحتوي هذا الكتاب على مجموعة مكتوبة من الصلوات والخطب التي تهدف في المقام الأول إلى تمكين الثخص المتوفى من التغلب على أخطار ما بعد الموت و الخروج بأمانٍ من القبر إلى عالَم ما بعد الموت، كما كان يحتوي أيضًا على أهازيج وكتاباتٍ ذاع صيتها في مصر آنذالك('ا)، وفي نفس السياق نشير در اسة أخرى إلى أن المتتبع 


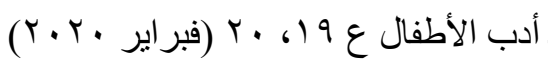
أدب الطفل الإفريقي

لجذور الأدب الإقريقي يجد أنها ضاربة في أعماق التاريخ، فقد كان هناك كاتبٌ مسرحي معروف في التراث المسرحي الأوربي في العصر الروماني هو (ترنتيوس) الذي جيء به من قرطاجنة بشمال إفريقيا كعبدٍ ثم أعتقه سيده وخلع عليه لقب أسرته، إلا أنه احتفظ بكنيته الإفريقية، وقد كتب جميع أعماله المسرحية باللغة اللاتينية، وما يؤكد ذلك صوره التي تخيلها المصوِرون عنه، بالإضافة لتفاصيل مسرحياته التي أظهرت أنه من أصلٍ زنجي إفريقي،

$$
\text { وقد كان (ترنتيوس) هو أول كاتبٍ مسرحي إفريقي يكتب بلغة أوربية(^ا') }
$$

وترى دراسة أخرى أنه إذا أردنا الحديث عن الأدب الإفريقي المدوَّن فلا يمكن أن ننسى المتفرق الألماني (هانيزيان) وما نشره من قائمة تحت عنوان الأدب الإفريقي الجديد ابتداءً من القرن السادس عثر الميلادي حتى عام (197V) (19)، وفي السياق نفسه ترى (19) إحدى الدر اسات أن دروب الأدب الإفريقي تشعبت وبدأت تزداد تعقيدًا منذ تحرر ها بدايةً من منتصف القرن التاسع عشر (r.).

\section{رابعًاـ أهمية الأدب الإفريقي:}

تشير إحدى الدراسات المتخصصة إلى أن الأدب الإفريقي كان ملاذًا للإفريقيين للتفيس عن همومهم وأحزانهم، والتعبير عن صر اعاتهم الداخلية التي عانوا منها خلال محاولاتهم التأقلم مع البيئة الجديدة لأوطانهم المستعدرة، ولقد أظهرث الدراسات النقدية للأدب الإفريقي تسليطه الضوء على المو اضيع المثيرة للجدل كالتمبيز العِرفي و العنصري، و الصر اعات السياسية، والحروب الطائفية، والتفرقة الجنسية، ولقد عززت هذه المواضيع الأدب الإفريقي، مما جعله من أهم أنواع الأدب ذي المغزى الذي بستحق أن يَحلَّل أدبيَّا ويُدرَس(r)، بينما أثنارت دراسة أخرى إلى أن الأدب الإفريقي استطاع أن يسلط الضوء على معاناة الأفارقة الحياتية، حيث كان هناك من المصاعب التي لم يكن بالإمكان إظهار ها لو لا شجاعة الكُتّاب الأفارقة الحياتية وخضو عهم للقلم والورقة لتسجيل معاناتهم التي أنتجت أعمالًا أدبية تساعد للترويج عن أنفسهم آنذاك(rr().

\section{خامسًا- خصائص الأدب الإفريقي:}

يتميز الأدب الإفريقي بخصائص معينة يُعرَف بها في الوقت الحاضر وستستمر معه في المستقبل؛ لأن هذا الأدب معقودٌ على هذه الأجيال، و إذا كان على الأجيال الماضية أن تثبت وجودها وتؤكده في الأدب وتدافع عن الوجود الإفريقي، فإن الأجيال القادمة سيكون عليها أن تقيم تقالبد جديدة غير منعزلة عن التقاليد القديمة؛ لتستمد منها قوة الحاضر 


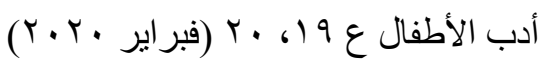
أدب الطفل الإفريقي

و المستقبل، و هكذا سيستمر الأدب الإفريقي في ماضيه البعبد والقريب، كما سيكون أيضًا في مستقبله أيَّا ما كان تغير هذه القيم، وهو أمر طبيعي لا يقبل الخلاف. وتثير إحدى الدراسات المتخصصة بوجود خصائص معينة للأدب الإفريقي، أهمها: ارتباط الأدب الإفريقي بقضاياه العامة ورفض السيطرة و الهيمنة الاستعمارية، و عدم ارتباط الأدب الإفريقي بهمومٍ فردية بل بهموم الجماعة، إضافة للوضوح الذي يصل إلى حدّ الثفافية في الأسلوب، خاصة الأعمال التي كُتبت باللغات الأوربية سواء الإنجليزية أو الفرنسية أو البرتغالية، و أيضًا التلقائية في التعبير، مما يظهر عليه السطحية في بعض أعمال الكُتّاب و الأدباء الأفار قة)(rr). سادسًا ــ أثر الاحتلال الأوربي لقارة إفريقيا على الأدب:

ترى إحدى الدراسات أن الأدب الإفريقي سواء الثفاهي أو المكتوب قد تعرَّض

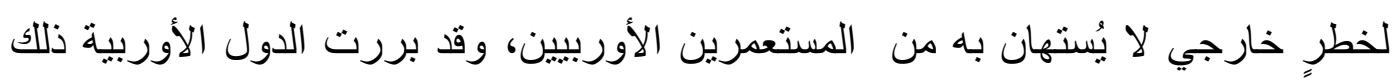
بأنهم جاءوا لنشر المسيحية والتبشير بها لسكان القارة الوثنيين والبدائيين، رغم أن السبب الحقيقي ور اء ذللك ليس سوى محاولة الأوربيين لاستغلال الثروات الطبيعية للقارة و استعباد

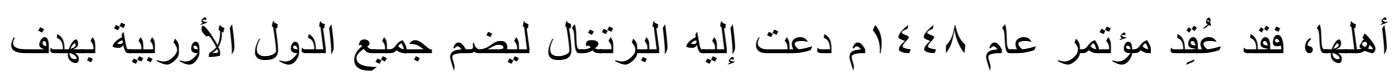

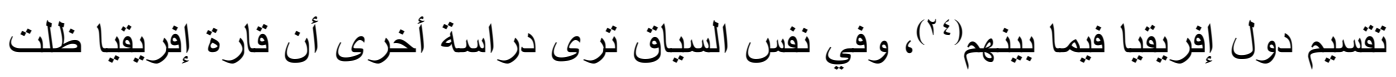
لفترةٍ طويلة مختبرًا لنظريات الدول الاستعمارية السياسية أوالاقتصادية أو الثقافية في بشاعةٍ لم يحدث لها مثثيل سواء في التاريخ القديم أو الحديث(ror). سابعًا محتوى الأدب الإفريقي:

تشير إحدى الدراسات المتخصصة إلى أن الأدب الإفريقي يحتوي على العديد من الأعمال المنتوعة بلغاتٍ مختلفة، بدايةً من الأعمال الأدبية الثفهية، مرورًا بالأعمال المكتوبة بلغة المُستعدِر سواء الفرنسي أو الإنجليزي أو البرتغالي، نهايةً بالأعمال المكتوبة باللغات الإفريقية المحلية، وتضيف نفس الدراسة أن نتوع لغات الأدب الإفريقي قد ساهمت في بناء أعمال ر اقية تحتوي على مصطلحاتٍ وتر اكيب لغوية مختلفة، كما ازدهرت الأعمال الأدبية من شعرٍ ومسرحياتٍ ورواياتٍ وقصص قصبرة حتى أصبحت من الأعمال الأدبية الثائعة في إفريقيا، و عادة ما تقدم هذه الأعمال معرفة و علمًا في شتى المجالات، وتضيف نفس الدراسة أن الأدب الإفريقي الثفهي قد سلك طرقًا عديدة مثل: الأمثال، والألغاز، و القصص الملحمية، والخطب، وشعر المدح، و الأغاني، والترانيم والثعائر الدينية، 


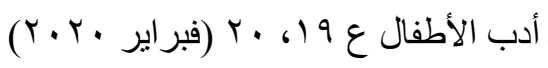
أدب الطفل الإفريقي

و القصص بأنواعها سواء الثعبية أو الأساطير، كما أن للأدب الإفريقي صورًا و أثكالًا، أهمها:

أـ الأدب الثفوي: ويثمل القصص، و المسرحيات، والألغاز، و القصص التاريخية، وتر انيم دفن الموتى، والأمثال، والعديد من من التعابير التي وظلِّت بشكلٍ أساسي لتعليم الأطفال وترفيهرح. بـ التاريخ الثفهي: ويثمل القصص الخرافية، والأمثال، التي نرسِّخ في أذهان المجتمع الإفريقي أمجاد أسلافهم البطولية وتاريخهم العريق، كما تشكّل هوية لحاضر هم من عاداتٍ وتقاليد.

ج- الأدب المكتوب: ويشمل الرويات، والشعر، و المسرحيات، و التر انيم، والقصص، كما شهد الأدب الإفريقي في الخمسينيات والستينيات من القرن التاسع عشر أحداثًا ومعاناة الشعوب الإفريقية التي استُعدِرَت أر اضيها، ووصِف الأدباء الأفارقة الذين كتبو ا باللغات الأوربية بأدباء الثورات، كما انتقلت النصوص الأدبية من كونها وسيلة شفاء للإفريقيين وطريقًا لهم لاستعادة أمجاد ماضيهم، إلى مرحلة أسمى حيث صبَّت جل اهتماماتهم على التمرد والانتفاضة ضد الاستعمار الأوروبي، حتى أصبحت أعمال الإفريقيين الأدبية تعتني بالحياة الو اقعية التي يعيشها الفرد في وطنه، و وتتقد ماضيهم الصامت بسلبية(r). ثامنًاـ أهم إشكاليات الأدب الإفريقي: ترى إحدى الدر اسات المتخصصة أن هناك العديد من الإشكاليات التي تواجه الأدب الإفريقي أهمها: إثكالية اللغة، و إثكاليات الأديب، و إثكاليات القارئ، و هي كالتالي:

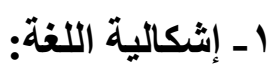

وقد انقسم أطر اف الإشكالية إلى فريقين، فريق يتزعمه (تثينو أتشيبي) يرى أن بعض اللغات الأوروبية مثل: الإنجليزية أو الفرنسية أو البرتغالية قد فُرضت فرضيًا على لِّلى لسان الأدب الإفريقي، ومن مصلحة الأديب الإفريقي الاستفادة منها والاستعانة بها لإيصال أدبه إلى العالم بسهولة، فيستطيع عرض مشكلة بلده على العالم وفضح أساليب الاستعمار التي تتنافى مع أبسط مبادئ الإنسانية، خاصة و أنها من أولى اللغات الرسمية والتي يتحدث بها ويفههها عددّ كبيرٌ من دول العالم، (اللغة الإنجليزية لغة أولى لأكثر من · . ع مليون 


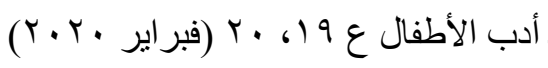

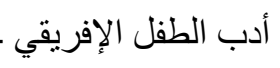

نسمة في جميع القار ات، و اللغة الفرنسية لغة أولى لأكثر من ، ب مليون نسمة، و اللغة البرتغالية هي لغة أولى لأكثر من · . . مليون نسمة)، هذا إلى جانب أن ليس من المهم التركيز على إيصال أعماله إلى القارئ الإفريقي بلغته الإفريقية التي يُقََّّر عددها بألفي لغة، فيكفيه فقط أن يتمكن من توعيته بعر اقة وغزارة ثقافة وهوية لغته الأم، تلك الهوية التي و اجهت حملة عنيفة من قِبل الاستعمار لطمسها ودفنها إلى الأبد، في الوقت الذي لا تجد فيه معظم اللغات الإفريقية نظم كتابة واضحة متفق عليها من الجميع؛ إذ إن من الموثوق فيه أن كثيرًا من شعوب القارة الإفريقية اعتادت من قديم الأزل على أسلوب النطق و المشافهة فقط دون استخدام الورقة والقلم مطلقًا، ومن أبرز الأمثلة على ذلك لغة القبائل (الانيو)، ناهيك على أن الاعتماد على اللغات الإفريقية في الأدب الإفريقي - إلى جانب أن لا يفهمها جميع الأفارقة حيث إن لكل دولة أكثر من لغة ـ فإن وسائل الأدب سوف تتقوقع وتتحصر داخل الدول التي لا يفهم سكانها لغة الأدب، مما لا يتحقق الهدف منه، وبالتالي فإن اللغات الأوربية تأتي هنا لتختصر كل هذا العناء وتطرح نفسها كلغات تو اصل مناحة في متناول الجميع على اختلاف لغاتهم.

أما الفريق الاخر، فمن منطلق سردية قومية معادية للاستعمار وكل ما نتج عنه من مظاهر، فيرى أن اللغات الأوربية للاول الاستعمارية لا يمكن أن تكون لغة الأدب الإفريقي، حيث إن التحرر الحقيقي لا يمكن أن يتم بدون إعادة إحياء اللغات الإفريقية الأصيلة و الاعتزاز بها، كما أن دور الأدب ومسئولية الأديب يجب أن تتطلق من داخل القارة الإفريقية وتكون بلغاتها؛ حتى تستطيع مخاطبة العامة الذين لا يجيدون إلا اللغات المحلية، مما يثير همهم ويحفز هم على التورة ضد الاستعمار ، كما أن استخدام الأديب للغة الأوربية للتعبير عن ثقافته وتوصيلها إلى شعبه ينتهي إلى تغبير رسالته التعليمية وإلى عدم الأمانة، لللك كانت اللغات الإفريقية هي الهدف الأساسي للدول الاستعمارية، خاصة الاستعمار الفرنسي الذي عمل على قتل اللغات الإفريقية ونشر لغته وبتّ ثقافته، مما أدى إلى وأد الروح الوطنية في الأدب الإفريقي، وفي نفس السياق ترى در اسة أخرى مع استخدام اللغات الأوروبية في الأدب أن الكتّاب الذين يستخدمون اللغة الإنجليزية مثثلً لا يصادقون أو يؤيدون بالضرورة الاحتلال البريطاني، و إنما تكون المسألة أكثر وظيفية بالنسبة لهم؛ بمعنى أن اللغة الإنجليزية تكون مجرد أداة للانتشار في العالم الخارجي من ناحية، و على المستوى الداخلي أيضًا، ومن أمثلة ذلك أن دولة مثل جنوب إفريقيا تجمع بين أكثر من إحدى عشر لغة 


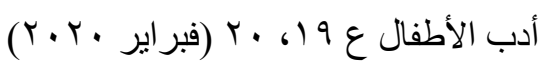
أدب الطفل الإفريقي رسمية معتمدة بها وكلها لغات محلية مكتوبة ومنطوقة يتم التأليف بها، رغم أن في واقع الأمر لا يجيدها الكثير من السكان المحليين لدواعٍ عِرقية وقومية، مما أدى إلى لجوء الكُتّاب و الأدباء إلى التأليف باللغة الإنجليزية بوصفها اللغة الأكثر شيوعًا لدى أغلب سكان دولة جنوب إفريقيا رغم أنها لغة الاستعمار. وترى در اسة أخرى أن الأديب الإفريقي المعروف (يوبولا سدار سنجور) يؤكد أن حل مشكلة اللغة في الأدب الإفريقي هو باتباع سياسة تربوية ترتكز على استعمال كلِّ من اللغات المحلية الإفريقية واللغات الأوربية(rv).

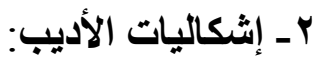

تشير إحدى الدراسات المتخصصة إلى وجود إثكاليات عادة ما تواجه الأديب

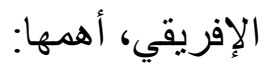

أـ الثعور المزدوج بالغربة داخل الوطن نتيجة اسنئنار المستعمر بكل شيء، و الغربة داخل اللغة نتيجة لاضطرار الكاتب إلى التفكير باللغة الأم والكتابة بلغة المستعدر، خاصة وأن الذين أُتيح لهم أن يكتبو ا بلغات الأم قد عانو الكثيرًا. بـ الالتزام والتقيد بالموروث الثقافي، حيث إن القبيلة هي التي تحدد للكاتب أو الأديب أو الفنان الأهداف العامة التي يلتزم بها في أدبه، مما أصبح يتشابه مع دور

$$
\text { الأديب في الأدب الثفاهي. }
$$

ج- على الأديب أو الكاتب أن يحارب الفردية التي انتشرت فترة الاستعمار. دـ على الأديب الإفريقي أو الكاتب محاربة مظاهر القيم الغربية التي اجتاحت معظم الدول الإفريقية، رغم تحرر ها والوقوف أمام المذهب الغربي بما يعرف (بالفن للفن)

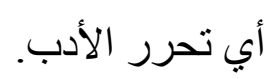

هـ مر اعاة التوفيق بين الأدب والسياسة، وهو من الصعوبة بمكان تحقيقه، حيث لا

$$
\text { يستطيع الكاتب أن يتجاهل الو اقع الخصب لصاحب الرؤى الجديدة (السياسي). }
$$

و- التعبير اللغوي: حيث ما زال الكاتب في حيرة بين أن يعبر باللغة الأوربية الواسعة الانتشارويحقق أهدافه، وأن يعبر بلغته الأم القليلة الانتشار نتيجة ارتفاع نسبة الأمية و انخفاض المستوى الاقتصادي الذي لا يسمح لهم بالقر اءة. ز- إقليمية الأدب: وهي من أخطر النظريات على الأدب الحديث، ويجب أن نفرِق بين تأثير البيئة في الأدب - وهذا لا اعتر اض عليه بل مقبول - وبين إقليمية الأدب، 


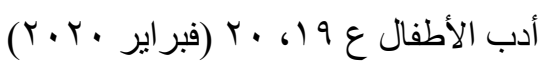

أدب الطفل الإفريقي

بدليل أن المتنبي وُلِد في الكوفة بالعراق ثم انتقل إلى حلب ثم إلى دمثق في سوريا، إلا أن آثاره لم ترتبط بقطرٍ معينٍ أو بمدينة معينة، بل عمَّت جميع الأقطار (^^).

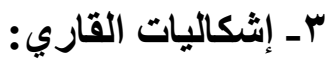

تشير بعض الدراسات المتخصصة إلى أن القارئ عادة ما بتعرض إلى بعض الإشكاليات خلال منابعته لأحد صور الأدب الإفريقي، أهمها:

أـ إشكالية الأدب الثفاهي: تُعد مشكلة الأدب الثفاهي مشكلة كبيرة أمام قارئ الأدب الإفريقي، وذللك رغم أهميتها في فهْ الأدب المكتوب، وتشير إحدى الدراسات المتخصصة إلى أن الأدب الإفريقي المكتوب باللغات الأوربية والإفريقية يشكّل مساحة ضئيلة على خريطة التعبير الأدبي المكتوب خارج نطاق اللغة العربية مقارنةً بالأدب الذي تناقله الثفاه من مكانٍ إلى آخر ومن جنسية إلى أخرى، حيث إنه أدب استمد من البعض الأدب الحديث لإفريقيا بصورة أثبه بالأدبين: الإغريقي و الروماني في كونهما ركيزة للأدب الأوربي الحديث الذي يُعد من أهم المؤشرات في الأدب العالمي المكتوب، وتضيف نفس الدراسة أن أول محاولة جادة ومهمة في جع ألوان الأدب الإفريقي الثفاهي كانت على بد المتفرق الألماني (أوجست سيدل)، حيث تم جمعه في صورة منتخبٍ كبيرٍ من الأدب الثفاهي تحت عنوان "القصص الإفريقية وحكاياتها"، و الذي دعا فيها القارئ الأوربي العالَم إلى رؤية فكر وتحليل وشعر الإفريقي الذي كانوا يدعون عليه بالتوحش والجهل والتخلف العقلي، وبالمثل أعاد زميله (فروينوس) الكرة في نشر منتخبٍ ضخٍٍ سمّاه "أطلنطيس"، حيث ظهر في اثنى عشر مجلد، وذللك عام (9 I I )، و احتوى على أكثر من أربعة آلاف صفحة(19).

وترى دراسة أخرى أن الأدب الإفريقي المكتوب قد حلّ مشكلة الأدب الثفاهي حلاً عمليَّا، مما أتاح للقارئ فرصة الاطلاع و التحليل و البحث، وقد ساعدت الترجمة على تيسير المراجع باللغات الأوربية بشكلٍ خاص، إلا أنه ماز ال جزءًا كبيرًا من هذا الأدب المكتوب باللغات الإفريقية بعيدًا عن متناول الدارس غير المتخصص في هذه اللغات، علمًا أن الأدب الثفاهي غير المكتوب لم يجمع حتى اليوم بطريقةٍ شاملة ومنظمة (r). 


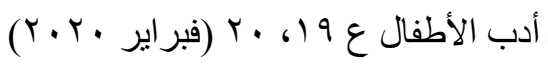

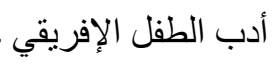

ب- إثكالية المراجع: نشير إحدى الدراسات إلى أن الأدب المكتوب قد حلَّ مشكلة المر اجع حلًا عمليَّا بما أتاحه للقارئ و الدارس معًا من قو ائم وفهارس منظمة باللغات الأوربية، كما ساعدت الترجمة على تيسير المراجع خاصةً الأوربية، أما بالنسبة للأدب المكتوب باللغات الإفريقية الأم، فما زال غير متوفر لاى الدارس غير المتخصص في هذه اللغات، وبالنسبة للأدب الثفاهي غير المكتوب فلم يتيسر جمعه حتى الآن بطريقة منظمة، مما جعل مشكلة المراجع الخاصة به تمثل عقبة حقيقية أمام الدارس، حيث إن ما تم نقله للعربية هو قليل ومبعثر وما زال في مرحلة مبكرة"(r)

ج- إشكالية المنهج: وتؤكد نفس الدراسة أن على الرغم من الوفرة النسبية للأعمال الأدبية الإفريقية وتاريخها الزمني الطويل، فإن عدد الدراسات التي أُجريت حول كل من الأدب الثفاهي والمكتوب محدودٌ للغاية وما زالت تعتمد على المتفرقين، وقد ظل هذا النمط سائدًا حتى منتصف الستينيات لدى قيام الجامعات و المعاهد و الكليات والأقسام الأدبية بدول القارة، مما أدى إلى ظهورصورة جديدة بعيدة عن الأدب الأوربي، وهي صورة المقال و البحث الموجز (الدوريات)، وصورة الكتاب (الأدب الإفريقي في القرن العشرين)(rr).

الفصل الرابع: أدب الطظل المغري:

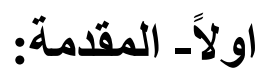

نظرًا لقلة الدراسات التي تناولت أدب الطفل في دول إفريقيا بشكلٍ عام، وفي دول جنوب الصحر اء الكبرى الإفريقية بشكلٍ خاص، فقد اعتمدت الدراسة على أدب الطفل في أحد دول شمال إفريقيا، وهي المملكة المغربية، باعتبار ها أحد أهم المر اكز التقافية في قارة إفريقيا منذ عهدٍ بعيدٍ، و التي يمكن اعتبار ها نموذجًا لأدب الطفل في إفريقيا يمكن من خلاله التعرف على شكل ومضمون و أهم إثكاليات أدب الطفل الإفريقي.

ترى إحدى الدر اسات أنه بعد ازدهار أدب الطفل المغربي على يد عددٍ من الأدباء الرواد البارزين أمثال: عبد السلام البقالي، ومحمد سعيد سوسان، ومحمد إبر اهيم بوعلو، و العربي بن جلون، الذين أثْروا المكتبة الأدبية المغربية والعربية والإفريقية بعددٍ هائلٍ من 


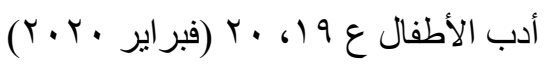
أدب الطفل الإفريقي

القصص و المجلات الموجهة للطفل، مثل: مجلة سامي والعندليب، ومجلة أزهار، ومجلة إرشاد... و غير ها، فقد عرف أدب الطفل المغربي في السنوات الأخيرة تراجعًا كبيرًا في مستوى الكتابة أو النشر أو الجودة، مما يمكن تسميته بأزمة، فكثيرٌ من الكُتَّاب و الأدباء لم يعد لديهم اهتمام بمر اعاة خصوصية الكتابة للطفل للأهداف التربوية و التقافية التي تساهم في بناء وتطوير شخصيته، بقدر ما أصبح كل ما بهههم هو التهافت على النشر وترجمة القصص الأجنبية دون مر اعاة لخصوصية الطفل المغربي العربي الإفريقي(r)".

وفي نفس السياق، نرى دراسة أخرى أن أدب الطفل في المملكة المغربية ما زال مهمشًا بدرجةٍ كبيرة مقارنةً بأدب الكبار، حيث إن الدراسات حول أدب الطفل بالمغرب

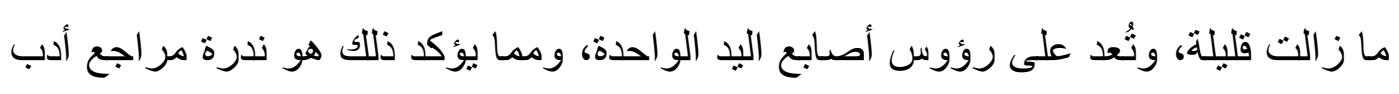
الأطفال بالمكتبات المغربية، ولعل ذلك يرجع إلى عدم اهتمام الدولة بالبحث بشكلٍ عام

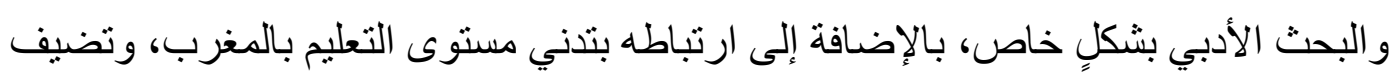
نفس الدراسة أنه من الممكن إرجاع أدب الأطفال بالمغرب إلى ثلاثة منابع أساسية: أولها أدب المشرق العربي خاصة كُتّاب و أدباء مصر أمثال: على الجارم، وأحمد شوقي، وكامل كيلاني... إلخ، ثانيها الأدب العالمي أمثال: لافوتيه، وجان جالك روسو، وجيمس أري، وشار بيرو، و أخيرًا التراث العربي والإسلامي، مثل: قصص القرآن الكريم، وقصص جحا، ونو ادر أبي نواس، وكتابات عبد الله بن المققع وقصص ألف ليلة وليلة(؟r).

\section{ثناتيًا تعريف أدب الطقل المغربي:}

تُعرِّف إحدى الدر اسات المتخصصة أدب الطفل المغربي بأنه "ذلك المنتج الإبداعي الذي يظهر في عدة أجناس أدبية وفنية وجمالية، ويضم الأنواع النثرية والثعرية والأنماط

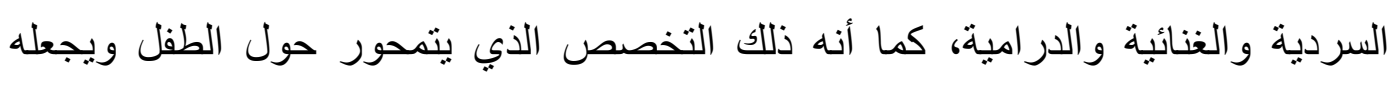
محورًا و مادة للدر اسة و الإبداع و التخيّل و التشخيص و التصوير، وهذا الأدب قد يكتبه الطفل للطفل، أو الكبير للطفل، أو الطفل للكبير، إذن فهو الأدب الذي يمكن أن يُطلَق عليه السهل الممتنع، الذي يخضع لمجموعة من الشروط والأركان خاصة الإلمام بالبيداغوجيا (أساليب التربية) و الديداكتيك (أساليب التحليل التربوي) و علم النفس، وعلم الاجتماع، وعلم النفس الاجتماعي")(ro( 


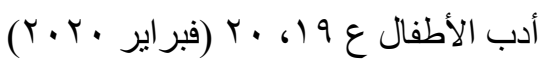
أدب الطفل الإفريقي

وفي السياق نفسه، ترى دراسة أخرى أن أدب الطفل هو "الأدب الذي يُقَّم للأطفال سواء كان شعرًا، أو أغنية، أو قصة، أو مسرحية، ويراعي ميول الطفل واتجاهاته الذهنية، و الجسمية، والوجدانية، والانفعالية، و الحسية، والحركية، وقد ظهر بالمغرب في السبعينيات من هذا القرن عدة منابر ثقافية تهنم به وتر عاه في قصص مثل: السندباد الصغير، و السندباد التلميذ، من خلال مجلات مثل: مجلة الأزهار و الإرشاد و العندليب"(『).

ثالثًاــ تاريخ أدب الطفل المغربي:

ترى إحدى الدر اسات أن تاريخ أدب الطفل المغربي يمكن تقسيمه إلى ثناث مر احل هي كالتالي:

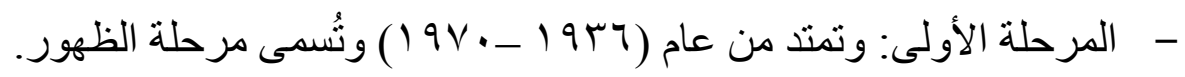

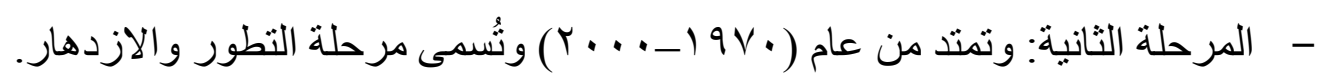

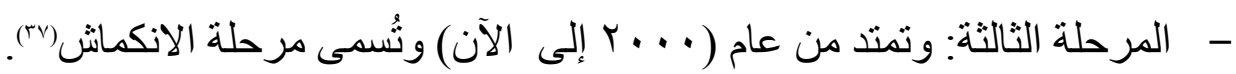
وفي نفس السياق، ترى در اسة أخرى أن أول ملامح الاهتمام بأدب الطفل بالمغرب بالمفهوم الحديث ورد على صفحات جريدة "العلم" المغربية التي أفردت للأطفال صفحة كاملة تحت اسم "صحيفة الأطفال"، وذلك بداية من عام (9 I I ( ) م، وفي نفس العام ظهرت جريدة "صوت الثباب" التي اهتمت أيضًا بالكتابة لكلٍٍ من الثباب و الأطفال، ثم ظهرت مجلة "الأنوار" التطاوية عام (^^ 9 ( ) م التي كانت تنشر في إحدى زو اياهاز زاوية مخصصة للأطفال تحت عنوان "قصص الأطفال"، ثم مجلة "هنا كل شيء" التي كانت تصدر في الدار البيضاء عام (ror (1))، و التي جعلت الأطفال على رأس اهتمامها، وقبل ذلك التاريخ لا يمكن الحديث إلا عن متابعة بعض الصحف المغربية للإصدارات المصرية، ففي عام (هبو (م) أثارت مجلة "المغرب الجديد" إلى صدور سلسلة القصص المدرسية (لسعيد العريان وأمين دويدار ومحمود زهران)، ومنذ الحماية الأجنبية على المغرب عرف أدب الطفل بالمغرب تطورًا كبيرًا، وازدهر عقب الاستقلال حتى نهاية القرن العثرين وتأثر نأثرًا كبيرًا بنظيره المصري، وكان أبرز من تأثر به من الكُتّاب هو كاتب أدب الاطفال المصري مصطفى

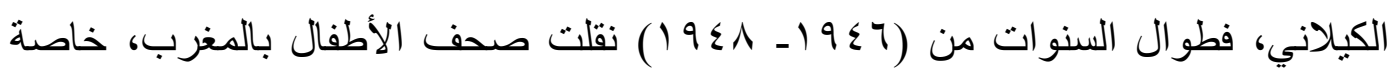




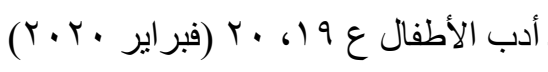
أدب الطفل الإفريقي

صحيفة العلم المغربية، اختصارًا، أو تصرفًا، أو نقلًا بسيطًا، أو نقلًا تامَّا، أو اقتباسًا، عن مجمو عة لا بأس بها من قصص هذا الر ائد المصري الكبير مفردة أو مسلسلة. ثم اعتمد أدب الطفل المغربي في المرتبة الثانية على قصص كل من: محمد عطية الإبر اشي، ومحمد سعيد العريان، ومصطفى دردير، ومحمد أحمد شيت، و غير هم، إلى أن صدرت جريدة "سندباد"، فأصبح قسمًا كاملً من الصحف المغربية يتابعها، أو يقتبس، أو يسرق منها، وقد أدت هذه المجهودات إلى الاهنمام بأدب الأطفال بالمغرب، خاصة بعد السماح بدخول المغرب مجلات الأطفال المصرية و العربية أمثال: العربي الصغير، وماجد، وسمير، وعلاء الدين، وبراعم الإيمان، وميكي، وستايل، وفراس، و الرواد، و الفردوس، و التي كان لها أكبر الأثر في لفت انتباه المربين والمعلمين والأطفال، مما جعل الكُتّاب و الأدباء و الفنانين المغاربة يحذون حذو ها.

وفي السبعينيات ظهرت العديد من المنابر التقافية المغربية التي تهتم بأدب الطفل مثل: السندباد التلميذ، ومجلة أزهار، والإرشاد، والعندليب، و المغامر، التي ظهرت عام 9V0 ام عن جمعية المغامر تحث إثراف أوبريم محمد، ثم مناهل الأطفال التي كانت تر عاها وزارة الثقافة، وأخيرًا مجلة مستعد التي كانت ترعاها الكثفية الحسنية، وجريدة

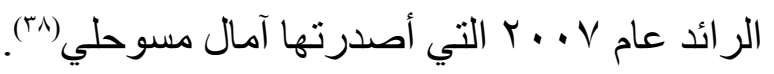

$$
\begin{aligned}
& \text { رابعًاــ أهداف أدب الطقل المغربي: }
\end{aligned}
$$

تشير إحدى الدراسات إلى أن أدب الطفل المغربي يهدف إلى ترسيخ أهداف في الطفل، أهمها: خلق المتعة لدى الطفل، مما بساعد على توسيع خبراته، ثم تعميق فهمه لحياة الناس و المجتمع و الطبيعة من حوله، و أخيرًا مساعدته على اشتقاق رؤية جديدة للعالم، خاصةً أمام القصور العظيم فيما يخص تنظيم الثعر للأطفال وإنتاج أغاني تساير العصر، خاصة وأن معظم أطفال المغرب ما زالوا يردِّون أناشيد وأغاني وقصائد شعرية قديمة جدَّا عفى

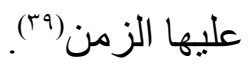

وفي نفس السياق، ترى دراسة أخرى أن من أهم أهداف أدب الطفل بالمغرب هو توخي البعد القيمي في تربية الطفل، وربطة بلغته، وترسيخ هويتة الثقافية، ومبادئ المو اطنة لديه، وتعزيز الإبداع المدرسي من خلال إثر الك الطفل نفسه في العمل، وذلك لتنمية القدر ات المعرفية و المهارية و الوجدانية لديه، وتطوير شخصيته حتى تتمو بشكلٍ متوازن(•؛). 


\section{خامسًا خصائص أدب الطقل المغربي:}

تشير إحدى الدر اسات المتخصصة إلى أن الكتابة للأطفال بالمغرب تتميز بخصائص معينـة، أهمهـا: مر اعـاة عمـر الطفـل والانطـلاق مـن التصــورات التربويـة البيداغوجيـة و الديداكتيكية، و الاستفادة من آخر نتائج الدراسات النفسية والاجتماعية للأطفال، الأمر الذي يتطلب اختبـار البحـوث الخفيفـة و المجـز أة في كتابـة الأثـعار و الأناثـبـ الموجهـة للطفل، و الابتعاد كثيرًا عن التعقيد اللفظي، والإفر اط في استخدام الصـور البلاغيـة والمجازيـة، وفي مجال المسرح ينبخي اختيار مسرحيات هادفة سو اء كانت أخلاقية، أو تاريخية، أو اجتماعية، أو تربوية، و التقليل من الشخصيات و المشـاهد و الفصـول و التعقيدات الإخر اجيـة، مـع احتر ام تسلسـل الأحداث في سياقها الزمـاني و المكاني، وتوظيف التـراث العربـي القديم والتراث العلمي الإنسـاني، مثنل: خيـال المآتـة، وصـندوق العجايب، وحكايـات الحيو انـات، وتوظيف ولفي الأقنعة، ومسرح العر ائس، و الكر اكيز.

وتضيف نفس الدر اسة أن من خصائص القصة التي تُكتَب للطفل المغربي أن تكون ردزيـة تثيـر خيـال الطفل، ويُفضَّلَ أن تكون على ألسـنة الحيو انـات و الشخصيات الخارقـة و العملاقـة، وأن تـاقش إثـكالية الخير و الثـر في تتـابعٍ كرنولـوجي، وذللك بالاعتمـاد على أسلوبٍٍ مشوقٍ مثتعِ يثير الفكاهة و السخرية من القيم المتدنية( (\&). وفي نفس السياق، ترى در اسة أخرى أن لأغنية الطفل المغربي خصائص تتميز بها عن باقي أشكال وصور أدب الأطفال الأخرى، وذللك لما لها من تأثير على منظومة أفكاره ومثاعره، حيث إنها الأدب الأفضل في تعليم الطفل، ويسعى الجميع إلى إعادة الاعتبار لأغاني الطفل المغربي، و الارتقاء بالذوق العام لها، وتهذيبها، وتحصينها من الإسفاف الذي أصبح تعرفه الأغنية العربية والمغربية، فغالبًا ما بلجأ أطفال المغرب إلى ترديد هذه الأغاني على مر أى ومسمع من الآباء و الأمهات.

وتضيف نفس الدراسة أن كل مَن يتصفح أدب الطفل بالمغرب سواء كان شعرًا أو نشيدًا فإنه سيُفاجَأ بأنه كان يتناول منذ ظهوره إبان الاستعمار مواضيع شتى لا تخرج في عمومها عن الثعر الوطني و السياسي و الاجتماعي و الديني و التربوي، حيث إنه قد تعايش مع كل الأحداث التي مرَّ بها المغرب، كثورة الريف التي تزعمها محمد عبد الكريم الخطابي و الظهير البربري عام ( • ب ( ))؛ من أجل المطالبة بالاستقلال و التغني بثورة الثعب و الملك، 


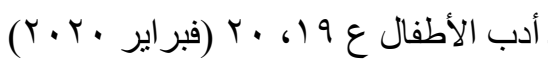
أدب الطفل الإفريقي

ورصد حركات التحرر العربي من جرّاء الوجود الاستعماري، والعزف على ترانيم الثعر القومي والإنساني، خاصة وأن شعر الطفل المغربي وأناشيده يحملان في طياتهما طابع الجهاد والاستشهاد والنفي والاغتراب والاعتقال والتحدي إبان الاستعمار، بينما عقب الاستعمار والتحرر فقد أصبح مرتبطًا بالأحزاب والمناسبات الوطنية والتظظيم الكثفي و الرياضي، كما كان أكثر ارتباطًا بالوطن و الراية، مثن النشيد الوطني المغربي "منبت الأحرار" الذي ألّهه الثاعر المغربي (علال الثقلي)، هذا وقد انصبَّ أيضًا على تناول مو اضيع أخرى منتوعة: كالطبيعة والفصول الأربعة، وقصص الحيوانات، على غرار شعر أمير الثعر اء أحمد شوقي وعثمان جلال، كما ركَّز على المدرسة بكل مكرّناتها الإدارية و التعليمية والدفاع عن اللغة العربية، على غرار قصيدة اللغة العربية لشاعر النيل حافظ

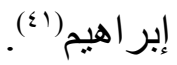

\section{سادسًا- واقع أدب الطقل المغربي:}

عرف أدب الطفل في المغرب في الفترة الحالية تعثرًا وتر اجعًا كبيرًا، سواء على المستوى الكمي أو الكيفي، وذللك لعو امل كثيرة موضو عية وذاتية سبق عرضها، الأمر الذي تطلب ضرورة التعرف على واقع أدب الطفل بالمغرب، إذن فما هو واقع أدب الطفل المغربي حاليًا؟ و اقع أدب الأطفال بالمغرب يمكن اختز اله في خمسة أجناس هي كالتالي:

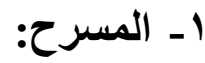

ترى إحدى الدر اسات أن مسرح الطفل في المغرب بختلف عن المسرح المدرسي،

وقد يلتبس معنى الاثثين على القارئ، حيث إن مسرح الطفل هو أعمّ و أشمل من المسرح المدرسي؛ فالمسرح المدرسي يقتصر وجوده على الروضة والمدارس بأنواعها الابتدائية و الإعدادية و الحرة، بينما مسرح الطفل هو في دلالته مسرح عام يتجاوز فضاء المؤسسة إلى فضاءات خارجية تربوية وغير تربوية، يثارك فيه الصغار والكبار، وقد يشرف عليه أشخاص لا يكونون محسوبين على المجال المدرسي، وقد انطلقت بداية مسرح المدرسة بالمغرب عام 9AV (، بينما بدأ مسرح الطفل عام بr9 ( لدى تقديم فرقة (مولاي إدريس) مجموعة من مسرحيات الأطفال، ومن أهم الذين كتبو ا مسرحياتٍ للطفل في المغرب: العربي بن جلون، ومحمد سوسان، والمحجوب البدري، أما من اشتغلوا بالمسرح، فمنهم (الإخوان الفاضلي)، وفي النقد عرف منهم: سالم أكومندي، ومحمد مسكين، و عبد الكريم برشيد(9؛. 


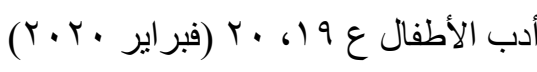
أدب الطفل الإفريقي

\section{Y - السرد القصصي والحكائي:}

ترى إحدى الدراسات أن قصص الأطفال بالمغرب لم تظهر إلا بداية من عام

I \ V ا، وذلك مع انطلاق صفحة الأطفال بجريدة العلم، كما ظهرت جريدة صوت الثباب المغربي على يد إبر اهيم السائح الذي خصصها للأطفال، بالإضافة إلى مجلة "هنا كل شيء" التي صدرت في الدار البيضاء عام 90 1 ، كما ظهرت في السبعينيات عدة منابر ثقافية تهنم بقصص الأطفال، مثل: السندباد الصغير، و السندباد التلميذ، ومجلات الأزهار، و العندليب،

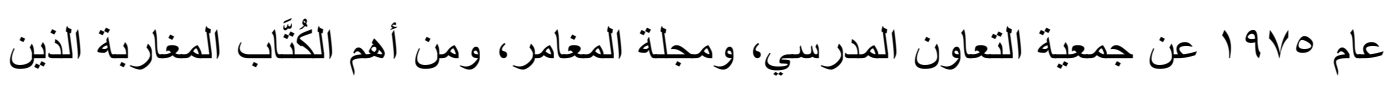
كتبو اللأطفال مصطفى غز ال، ومصطفى رسام، ومحمد شفيق، و عبد الكريم حليم. وقد اعتمد كُتَّب قصص الأطفال على النقل والترجمة والاقتباس، وقد تأثرو ا بالأدب السردي العربي القديم (كليلة ودمنة، وألف ليلة وليلة)، كما تأثرو ا بالآداب الأجنبية و الكتابات القصصية المشرقية خاصة من مصر، مثل: كامل كيلاني، ومحمد عطية، ومن أهم قصص الطفل بالمغرب: سلسلة سناد لعبد الفتاح الأزرق، وسلسلة كان باما كان لمصطفى رسام، وسلسلة القصص المدرسية لعبد الحق الكتاني.

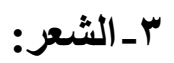

وعن شعر الأطفال، ترى نفس الدراسة أن شعر الأطفال بالمغرب يرتبط بالأناشيد و القصائد الوطنية والأغاني الخفيفة التي كان يردّدها الأطفال داخل وخارج المغرب إبان الاحتلال وبعد الاستقلال حتى الآن، ومن أهم الثعراء المغاربة الذين كتبوا للأطفال هم: محمد الطاهر الزيتوني، وعلى النقلي صاحب النشيد الوطني المغربي، وقد صدرت له عام • 99 مجموعاتُ غنائية وشعرية للأطفال، و أحمد عبد السلام البقلي في ديوان (الصغار) الذي نُثِر ضمن كتابه "أيامنا الخضر اء"، ومن أهم الثعر اء المغاربة المعاصرين للأطفال (محمد عبد الله الرباوي) في ديوانه عصافير الصباح، وديوان محمد لقاح (سأفتح باب فؤ ادي)، وديوان جميل حمداوي (يحيا السلام)(م).

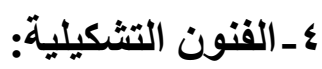

تشير إحدى الدر اسات إلى أن فن الرسم التشكيلي بالمغرب قد نال أهمية كبرى ضمن البرامج الموجهة للطفل في الماضي، وماز ال هذا التقليد ساريًا حتى الآن في إذاعة المغرب الوطنية ضمن أهم البرامج المتعلقة بالأطفال، ومن أهم رواد هذا الفن من المغاربة (عبد الله 


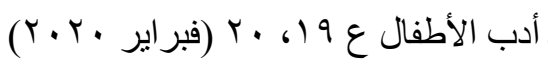

أدب الطفل الإفريقي

الفيلالي) الذي كان يشارك في العديد من البرامج الإذاعية للأطفال من خلال عمل مسابقاتٍ بين الأطفال في مجال الرسم التشكيلي(').

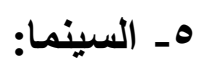

تشير بعض الدراسات المتخصصة إلى أن الحديث عن سينما الأطفال بالمغرب لا

يُقَصَد به الأفلام الكارتونية كما يظن البعض، و إنما يُقصند بها الأفلام الروائية الخاصة بالطفل الذي يُحاط يوميَّا بآلاف الصور المرئية الكارتونية وغيرها، حتى أصبحت تشكّل وعيه الباطن، وتغذي شخصيته المتسمة بالعنف في عصرنا الر اهن، سواء في الأفعال أو الحركات أو الألفاظ، إضافة لغياب الأخلاق و المسح الحضاري الذي أصبح عنوانًا لمعظم المجتمعات، وتضبف نفس الدراسة أن المتأمل في الفيلموغرافية المغربية يلاحظ أن موضوع الطفل حاضر بقوة على الساحة المغربية بالر غم من قلة الأشرطة الخاصة به، وهذا الحضور يظهر من خلال عدد وعناوين أفلام الأطفال المغربية، مثل: شاطئ الأطفال الضائعين 999 (6 و الطفولة المغتصبة سو 19 لحكيم النوري، و الطفولة المتمردة م ـ. . ب لمؤمن السميحي. لذلك يمكن القول بأن المغرب كان بإمكانه أن يكون رائدًا في مجال سينما الطفل على المستوى

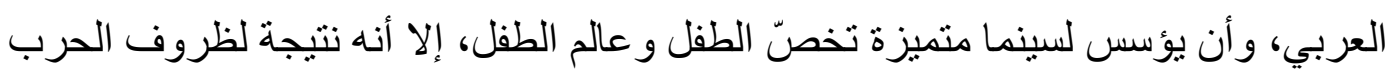
وضعف الإمكانات و عدم اهتمام وزارة الثقافة فلم يتوفر في المغرب مهرجانًا واحدًا لسينما الطفل سوى مهرجان المعاقين الذي يهتم أساسًا بالطفولة)(ror).

\section{سابعًاـ أهم إشكاليات أدب الطفل المغربي وسبل حلها:}

مما لاشك فيه أن هنالك أزمة حقيقية في أدب الطفل بالمغرب، وذلك كنتيجة طبيعية

لوقوع تقصيرٍ في حق الطفل وأدبه من جهاتٍ عديدة، منها: دور النشر، و الكُتّاب و الأدباء، و الأسرة و المجتمع، و الإعلام ووزارتي التربية و الثقافة.

وتثير إحدى الدراسات إلى أن المتتبع لأدب الطفل بالمغرب سيكتثف انحسارًا

ونر اجعًا كبيرًا فيه، ليمحو كل ما عرفته الأجيال السابقة من إبداعٍ خاصةً قصص وروايات الأطفال لعبد السلام البقالي و العربي بن جلون و غير هما.

و على الرغم من المجهودات التي بُذلت من أجل تطوير أدب الأطفال بالمغرب في

الماضي، فإنها لم تستمر طويلً ليستفيد بها الأجيال الحالية مثل أي دولة عربية أو إفريقية أخرى؛ وذلك لتعثرها أمام عددٍ من الإشكاليات من المتاريس البيروقراطية والسياسية، 


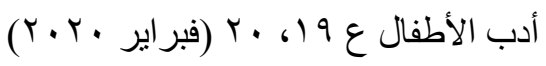
أدب الطفل الإفريقي

إضـافة لضعف الإمكانات المادية، وانعدام الحافز المعنوي، وتردي الأوضاع الاجتماعية و الاقتصادية في المغرب بعد فترة السبعينيات؛ نتيجة لدخولها في الصراع حول الصحراء بين جبهة البوليساريو والجزائر، وقد استنزف هذا النزاع ميزانية الدولة عبر السنوات الطويلة، مما كان له أكبر الأثر على الثقافة والتعليم والقوة الثرائية للمواطن المغربي، وبالتالي توقف أدب الطفل على كافة الأصعدة وفي شنى الصور والأجناس الأدبية، ورغم بروز بعض المحاو لات الجادة بين الحين والآخر فإنها لم تستمر طويلًا لتعود الأزمة مرة

وترجع إحدى الدر اسات هذه الأزمة إلى جانبين مهمين:

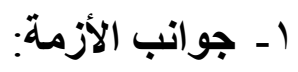

أـ الجانب الموضوعي: ويتعلق باختلال شروط التلقي، وتر اجع القراءة كنشاطٍ أساسي للمعرفة أمام ذيوع وانفجار المعرفة البصرية المتاحة عبر القنوات والمنتديات و المو اقع؛ إذ انحسر اطلاع طفل اليوم على العالم عبر حاسة الرؤية المباثرة، بينما لم يعد يشغل حاسة التخيّل التي تتصل أساسًا بالقراعة في كتابٍ ورقي، الأمر الذي انعكس سلبًا على وعي الأطفال وعلى طبيعة تمثيلهم لمحيطهم، وعلى التخيّل والإبداع و اتخاذ القرارات.

بـ الجاتب الأتي: وهو يتمثل في طبيعة المادة المتخيلة التي نقدمها للطفل؛ إذ لم يعد مستساغًا ولا منطقيَّا الحديث عن الجن والأشباح و الساحرة الثريرة والأمير و عقلة الإصبع مثثلً، حيث إننا اليوم أمام طفلٍ أكثر ذكاءً منا وأكثر اطلاعًا ومشاهدة وتفاعلً مع الأفلام الكارتونية، سواء كان خيالًا علميَّا أو أية معالجة لظو اهر خارقة وميتافيزيقية، وهكذا أصبحنا نخاطب طفلًا ذا بنية عقلية مركبة، ولا بد من بذل الت مجهودٍ كبيرٍٍ لإقناعه، ولن يتأتى ذللك إلا بانتقاء مواضيع يحسّ بها وتمسّ شعوره و إدر اكه، شريطة أن تُصساغ بلغةٍ ذكية تحترم عقله وقدر اته وخياله الو اسع (َّهُ.

بينما ثُرجع دراسة أخرى الأزمة إلى برامج التعليم التي لا تأحذ بعين الاعتبار في كثيرٍ من الأحيان المرتكزات الكبرى التي يقوم عليها أدب الأطفال، أي لي لهري الموضوعات التي يمكن أن نتحفه بها من حكاياتٍ أو شعرٍ أو غير ذلك، ثم الاعتقاد السائد لدى الكثيرين ممن يعملون في مجال أدب الأطفال سواء كان في التأليف أو 


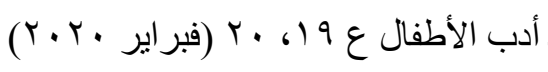

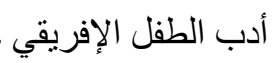

الطباعة أو النشر أو التوزيع، بأن هذا النوع من الأدب لا يُدرّ عليهم ما ينتظرونه من ربحِ ومال، وأخيرًا لعدم ترسيخ الاهتمام في تقاليدنا بالطفل كعنصرٍ بشري مهم في

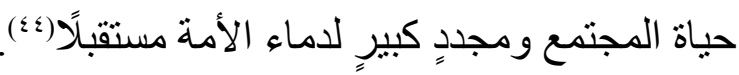

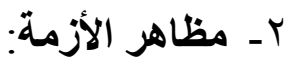

ترى إحدى الدراسات أن أزمة أدب الطفل بالمغرب لها العديد من المظاهر،

أـ التهافت العشو ائي للكثير من الكُتّاب و الأدباء على إعادة صياغة قصص قديمة في قالـبٍ آخـر مهلهـل، تنقصـهـ اللغـة المناسـبة لتطـوير الطفـل، وتقنيـات الكتابـة، و المجمو عات الملائمة للمتلقي الصغير. بـ تسارع دور النشر على طبع مثل هذه الأعمال الهزيلة؛ بغية الربح الكثير و السريع دون إعطاء الطفل أب اهتمام هل هي مفيدة له أو لا، وما إذا كانت

$$
\text { ستؤثر عليه إيجابيَّا أم سلبيَّا. }
$$

تـ عدم وجود متابعة ورقابة وتوجيه من الجهات المسئولة لجميع الأطر اف العاملة في هذا المجال سواء بوزارة الثقافة أو التربية والتعليم، بدعوى حرية التأليف و النشر، مما أدى لوجود ما يمكن تسميته بالفوضى و الارتجالية. ثـ ظاهرة الاستخلال التجاري لأدب الطفل بالمغرب أكثر من أي أدب آخر، لدرجة أن هناك من الكُتّاب كَن يقوم بتاليف أي شكلٍ من أشنكال أدب الأطفال دون أن يهتم بذكر اسمه؛ لأن كل ما يهمه هو الربح فقط، ولذلك نجد أن الكثير من دور النشر بعيد طباعة قصص سابقة لجحا أو لحديدان (أسطورة مغربية) أو للأنبياء و الصحابة لمجرد تحقيق هامش ربحٍ كبيرٍٍ لا للتثقيف ولا التربية ولا التعليم، وتضيف الدراسة أن الأديب المغربي العربي بن جلون كان في أحد معارض الكتب فلاحظ أن أحد الأطفال بصدد شر اء أحد الكتب التي لا تتناسب ومرحلته العمرية، و عندما سأله عن السبب في شراء الكتاب، أجاب بأنه لمجرد ذكرى يحتفظ بها للمعرض، فاقترح عليه كتابًا آخر أكثر تناسبًا مع المرحلة العدرية له و أقل ثمنًا، مما جعل صاحب المكتبة يتدخل والثرر يتطاير من عينيه ويعاتبه ويطالبه بعدم التدخل في اختبار ات الأطفال، ولعل ذلك يرجع لشعور البائع أنه 


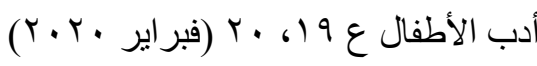

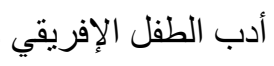

خسر صفقة بيع كتابٍ إلى الطفل بعشرة أضعاف الكتاب الذي اشتراه دون الاهنمام بما إذا كان الطفل سيستفيد منه أم لا !!(؛؛).

وفي نفس السياق، ترى دراسة أخرى أن من أهم المظاهر التي تعكس

أزمة أدب الطفل في المغرب هي بداية غياب سياسة ثقافية تربوية تشجع على الكتابة للطفل بل وتدعم القائمين على هذا العمل، سواء كانو ا مؤلفين وأدباء، أو ناشرين، أو موزعين كما هو الحال في الدول المتقدمة، مرورًا بتدني مستوى المتعمين، خاصةً في مستويات القراعة و إتقان اللغات، نهايةً بندرة البرامج التعليمية التربوية التي كانت تصدرها بعض المراكز التربوية والهيئات و المنظمات الكثفية التي تعتني بالطفولة وتصدر عنها صحف ومجلات للطفولة، إلا أنها توقف صدور ها الآن("). بـ مقترحات وسبل حل الأزمة:

تشير بعض الدراسات المتخصصة إلى أن هناك أربعة أمور للخروج من أزمة أدب الطفل في المغرب وحل إثكالياتها، هي: احترام ذكاء الطفل، ثم اختيار مضامين متصلة بالو اقع، وأيضًا الاستعانة بأسلوبٍ يحترم المنطق و العلاقات السبيية بين الدوافع والنتائج، وأخيرًا الابتعاد قدر الإمكان عن شَخْل خيال الطفل بالخر افات.

وتضيف نفس الدراسة أن من المضامين المناسبة و المفيدة للطفل، والتي يمكن أن تُخرِج أدبه من أزمته هي القصص ذات المضامين الاجتماعية التي هي الأقرب بلا منازعٍ إلى خبال الطفل، وذلك عن طريق كتابة جُملٍ من القصص التي تتسجم مع هذا التوجه، مع اختيار لغة تتحاز إلى المجاز حينما يتعلق الأمر بالوصف، خاصة الوصف السيكولوجي للثخصيات المأزومة و المهمَّنة اجتماعيًّا،

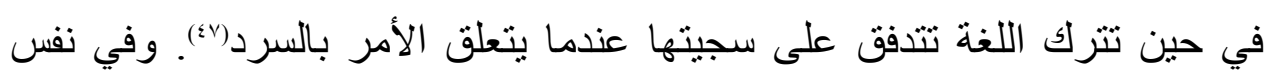
السياق، ترى در اسة أخرى أنه كي يتم المساهمة في حل الأزمة فعلى كلِّ من الكاتب و الأديب العمل على التطوير من نفسه طوال فترة حياته الأدبية، والاستفادة من التجارب العربية والغربية في أدب الطفل، وأخيرًا الاقتر اب من الأطفال والتعرف على طلباتهم وميولهم وانفعالاتهم، حتى إنه من الممكن عرض الأعمال الأدبية لهم على عينة عشو ائية منهم قبل طباعتها(^ء). 
في ضوء مـا توصلت اليه الدراسة من نتائج توصي بالآتي:

1- تثنكيل مجلس أعلى لأدب الطفل من جميع الدول الإفريقية، ويضم المسئولين عن

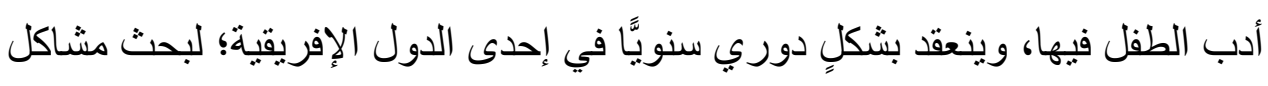

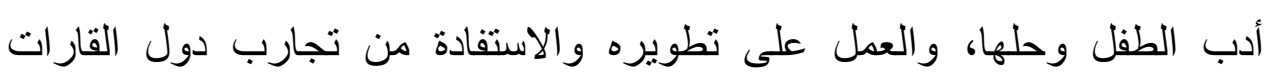

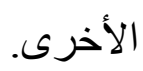

rـ التوسع في إقامة التظاهرات الدورية على مستوى المسئولين عن الثقافة وأدب

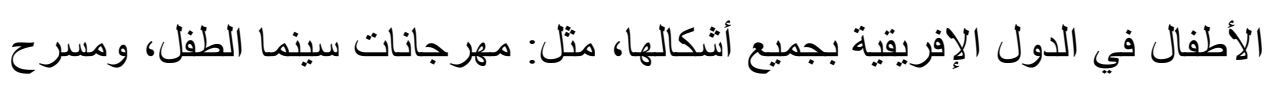
الطفل، ومعرض كتب الطفل، مع تخصيص الجوائز التشجيعية للمبدعين من جميع

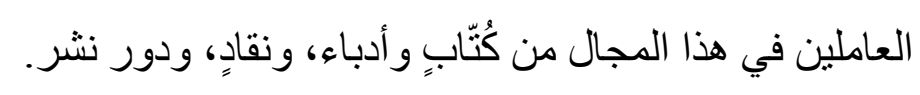

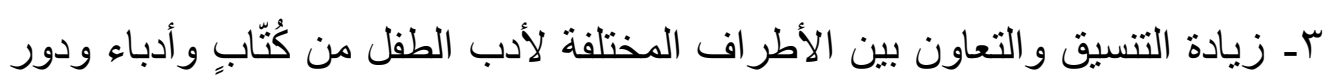

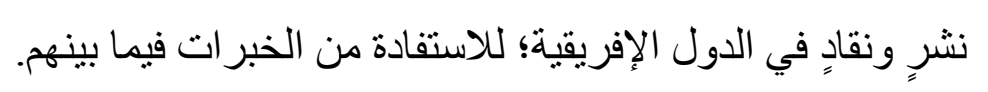

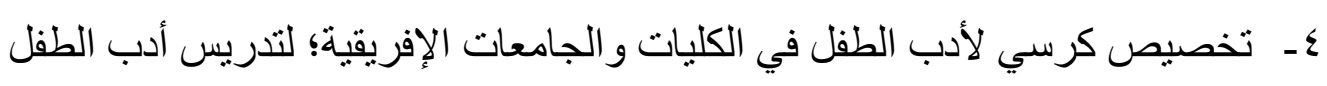
في المرحلة الجامعية و الدر اسات العلبا. ــ اتباع الدول الإفريقية لسياسة ثقافية تربوية؛ لتنشيع أدب الطفل، وتدعيم القائمين

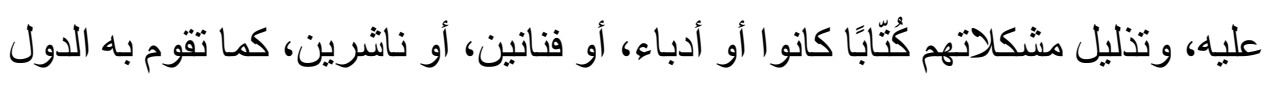
المتقدمة. 7ـ التأكيد على إسناد المناصب القيادية في الجهات الإفريقية المسئولة عن أدب الأطفال

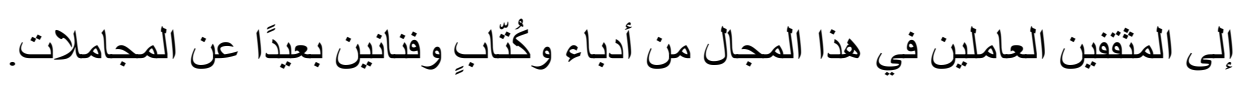

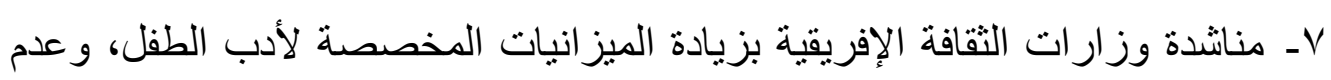

$$
\text { اعنباره جزءًا أو تابعًا لأدب الكبار. }
$$

^ــ ت تذليل الصعوبات وحل المشكلات المختلفة لتبادل الأشكال المختلفة لأدب الطفل بين لادبار.

$$
\text { الدول الإفريقية. }
$$

9- التنسيق و التعاون التام بين وزارتي: التقافة، والتربية والتعليم الإفريقية؛ لإمكانية

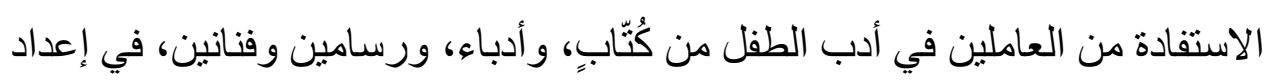




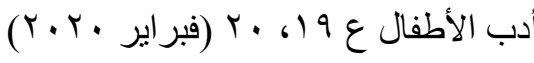

أدب الطفل الإفريقي

الكتب و المناهج الدراسية في المر احل الدراسية الأولى للأطفال؛ وذللك لما لديهم من خبرة في هذا المجال.

• ـ ـ التوسع في عملية الترجمة لجميع أشكال أدب الطفل في الدول الإفريقية باللغات الرئيسة، مثل: الإنجليزية، والفرنسية، والعربية؛ لنجاح عملية تبادلها بين الدول الإفريقية و الاستفادة منها.

1 ا ـ مطالبة الأدباء و الكُنَّب والفنانين و الرسامين الأفارقة في أدب الطفل، بتطوير أنفسهم طوال فترة حياتهم الأدبية، والاستفادة من خبرات الآخر بنفس المجال في

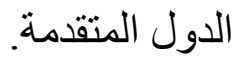




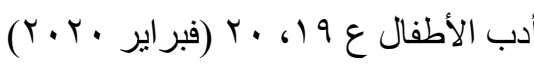

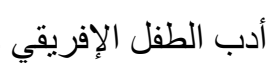

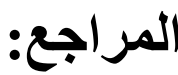

1 ـ محمد رياض وكوثر عبد الرسول، إفريقيا ـ در اسة لمقومات القارة، القاهرة،

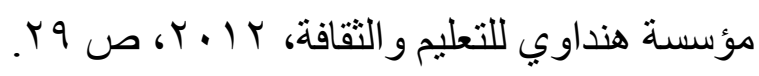

Y - مارمول كريخال، إفريقيا، طب، القاهرة، مطابع المعارف الجديدة، 919 19

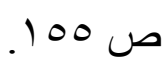

بـ عبد الله عبد الرازق وشوقي الجمل، تاريخ إفريقيا الحديث و المعاصر،

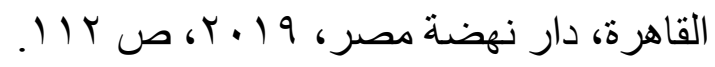

ع - عبير شوقي ذكي، العلاقة بين الدين والسياسة في إفريقيا، طا، القاهرة،

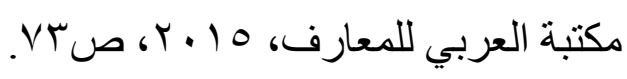

ــ شار أندرليه جوليان، تاريخ إفريقيا الثمالية، ترجمة محمد مز الي والبشير بن

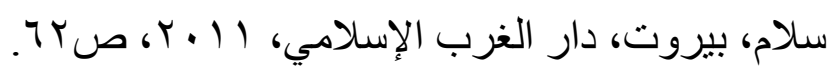

7- جمال حمدان، إفريقيا الجديدة- دراسة في الجغر افيا السياسية، غير منشور

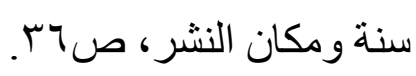

V- كلود فونيه، إفريقيا للإفريقيين، ترجمة أحمد كمال يونس، القاهرة، دار

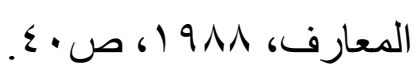

1ـ محمد مختار و أمين مكرم، أضواء حول إفريقيا، القاهرة، مكتبة الأنجلو

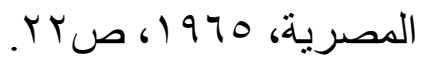

9 - جمال حمدان، إفريقيا الجديدة ـ در اسة في الجغر افيا السياسية، مرجع سابق، ص זr

• 1 ـ عبد الحي عبد الحق، القرابة اللغوية أو العربية في غرب إفريقيا، غير

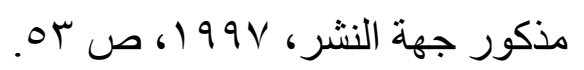

ا ا - حسن مكي، التواصل العربي الإفريقي على جانبي الصحراء- دراسة

إفريقية، العدد التاسع، القاهرة، غير منشور جهة النشر، 991 (، ص ال7. 


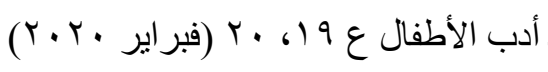

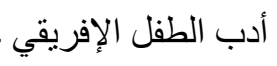

Y ا ـ محمد البثير سميلا، الأوضاع السياسية وأثرها على التعليم الإسلامي في اليمن (950 _90019)، رسالة ماجستير غير منشورة، كلية الدراسات

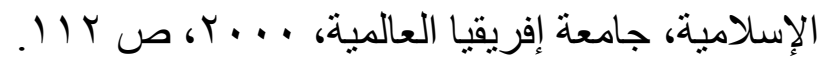

ץ ا ـ محمد عبد الغني سعودي، قضايا إفريقية، سلسلة عالم المعرفة، العدد ع؟،

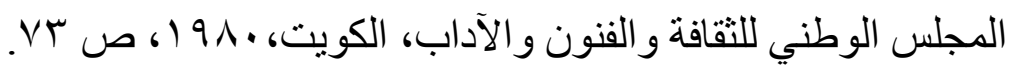
ع ا ـ عبد الله سليمان أحمد، الأدب الإفريقي النص الغائب، الخرطوم، دار المقدم للطباعة و النشر، 999 (، ص 79 ب.

0 7 ا ـ عبد الحليم حفينة، الأدب الإفريقي، مقال في جريدة روز اليوسف، بتاريخ

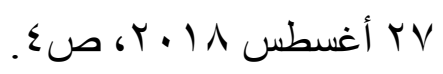

IV - رول شونيكا، الأسطورة والأدب الإفريقي، ترجمة نسيم مجلي وإيلين مجلي، القاهرة، الهيئة المصرية العامة لدار الكتب و الوثائق القومية، ط، 7 ـ ب . 1 ا ـ يوسف ميكنيلا، الأدب الإفريقي بين الأصالة الإسلامية والمتعة الفنية،

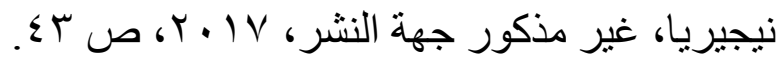
9 ( ـ عامر صمب، الأدب السنغالي العربي، الجزائر، الثركة الوطنية للنشر

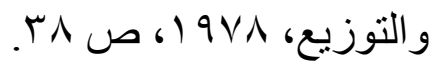
• † ـ يوسي منهيلا، الأدب العربي النيجري ومؤثرات الاستعمار الفرنسي عليه،

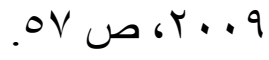

ا Y ـ عبد الكريم الشرقاوي، الملحمة اليونانية في الأدب العربي، الجزائر، دار

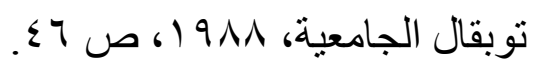

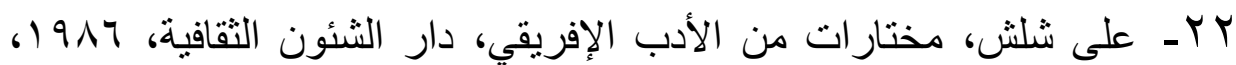

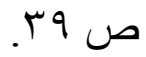
بr ـ ـ حاج أبا آدم الحاج، دور الأدب الإفريقي في التحرر الوطني، كلية الموسيقى و الدراما، جامعة السودان للعلوم، الخرطوم، غير مذكور سنة النشر، ص ع؟. צ Y - عبد المجيد قطاش، الأمثال العربيةـ دراسة تحليلية، طا، دمشق، سوريا،

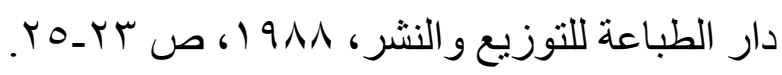




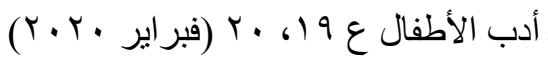

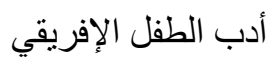

هץ ـ محمد جريلس، أنثروبولوجيا الحكاية، دراسة أنثروبولوجيا في حكايات شعبية تونسية، تونس، مطبعة تونس، 990 (، ص صـ جr - عمر عبد الحافظ، الأدب الإفريقي ومسألة اللغة، عمان- الأردن، غير

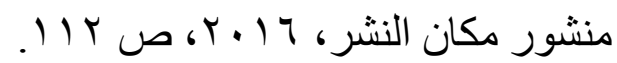
PV - باسمين فيدوح، أشكال الترجمة في الأدب المقارن، دمشق- سوريا، دار

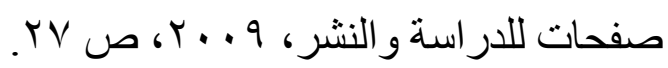
^ץ ـ أسامة الجوهري، الفن الإفريقي، القاهرة، دار هلا للنشر والتوزيع، القاهرة،

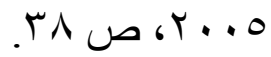

9ץ- سنجور يوريس سوبار، المسرح السنغالي ودوره في قضايا المسرح الإفريقي، ترجمة فيفي فريد، طا، أكاديمية الفنون، القاهرة، 990 (، ص سب. • "ـ حسن إلهامي، تاريخ المسرح، سلسلة كتابي، العدد ا • (1، دار المعارف، القاهرة، غير مذكور سنة النشر، ص ص VY آ- على شلش، الدراما الإفريقية، سلسلة كتابك، عدد ... (، دار المعارف،

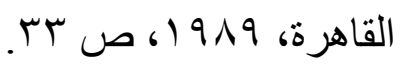

Y بــ إبر اهيم أحمد، التأويل و الترجمة مقاربات لآليات الفهم والتفسير، طا، بيروتـ لبنان، الدار العربية للعلوم ناشرون، 9 . . T، ص س V. سبـ جميل حمداوي، أدب الأطفال في الوطن العربي، طا، الناظور ـ المغرب،

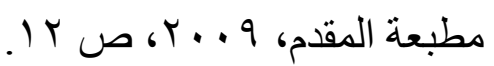
ع ــ ـلى الحديدي (في أدب الأطفال)، طا، القاهرة، مكتبة الأنجلو المصرية،

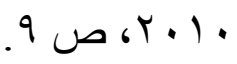
هب- جميل حمداوي، بيليوغرافيا أدب الأطفال في المغرب، طا، الرباط،

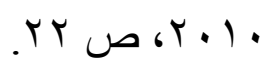
جسـ نجلاء نصبر بشور، أدب الأطفال العربي، طا، القاهرة، مركز دراسات الوحدة العربية، ب ا ـ ب، ص 10. TV ـ لطيفة الهدراني وآخرون، دراسات وبيلوغر افيا، أدب الأطفال والثباب

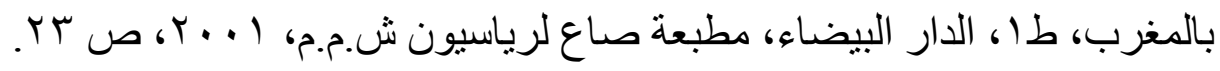




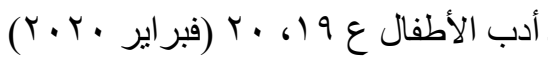
أدب الطفل الإفريقي

^ץـ ـ سمر روحي الفيصل (أدب الأطفال وثقافتهم) در اسة نقدية، منشور ات اتحاد

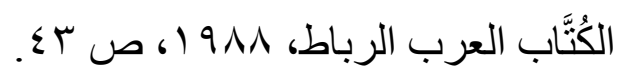

q ץ ـ محمد حسن بريغش، (أدب الأطفال)، أهدافه وسماته، طץ، مؤسسة الرسالة، ד999 199 ص VI.

• ـ - حسن شحاتة (أدب الأطفال- دراسات وبحوث)، طب، بيروت، الدار المصرية اللبنانية للطبع، \&99 1، ص الY اع ـ أحمد فضل شبلول، الأدب الإفريقي، الإسكندرية، ب . . Y. Y ـ - عبد الفتاح معال، أدب الأطفال ـ در اسة وتطبيق، طب، الرباط، دار الثروق

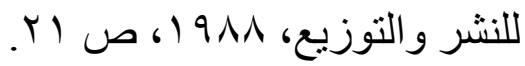
بـ ـ ـ أحمد عبد السلام البقالي، أيامنا الخضر اء، الدار البيضاء، المطبعة الملكية، .07 ص (977

§ ـ ـ أحمد زلط، أدب الطفولة بين كامل كيلاني ومحمد الهر اوي ـ در اسة تحليلية ناقدة، طا ، القاهرة، دار المعارف، ص سب أ. § ـ ـ أحمد زلط، (أدب الطفولة أصول ومفاهيم) رؤى تراثية، طء، القاهرة، .117 ص .199V 7ع - سعيد سالم الكرواتي، نوارس الربيع، طا، الدار البيضاء، مكتبة سالم للتقافة، V . . r ص ص rr. \&V مطبعة المعارف، (9919، ص 7 (1). ^乏 ـ العربي بن جلون، شعر الأطفال ـ در اسات مشتركة، طا، الهيئة المصرية

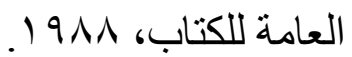

9 § - جميل حمداوي، مسرح الطفل بين التأليف والإخراج، طا، الرباط، مطبعة

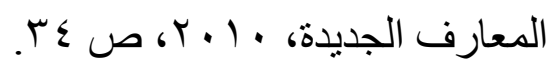

• 0ـ إبراهيم السولاني، الثُعر الوطني المغربي في عهد الحماية، طا، دار

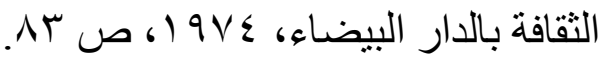




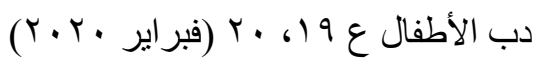

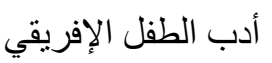

10ـ - محمد أنقار، قصص الأطفال بالمغرب، طا، تطوان، مطبعة جامعة

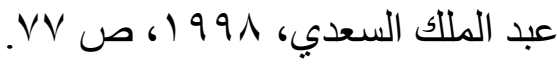

ror مصطفى المسناوي، أبحاث في السينما العربية، غير منشور مكان النشر،

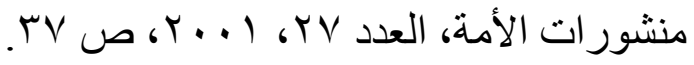

